\title{
Phenolic Profile, Antioxidant and Enzyme Inhibition Properties of the Chilean Endemic Plant Ovidia pillopillo (Gay) Meissner (Thymelaeaceae)
}

Carmen Cortés ${ }^{1,+}$, Diego A. González-Cabrera ${ }^{1,+}$, Ruth Barrientos ${ }^{1} \mathbb{D}$, Claudio Parra ${ }^{2}$ (D) Javier Romero-Parra ${ }^{3}$ Mariano Walter Pertino ${ }^{4, *(D)}$, Carlos Areche ${ }^{5}$ (D) , Beatriz Sepúlveda ${ }^{6}$, Jorge Bórquez ${ }^{7}$ (D) , Alfredo Torres-Benítez ${ }^{1}$ (D) and Mario J. Simirgiotis $1,8, * \mathbb{D}$

check for updates

Citation: Cortés, C.; González-Cabrera, D.A.; Barrientos, R.; Parra, C.; Romero-Parra, J.; Pertino, M.W.; Areche, C.; Sepúlveda, B.; Bórquez, J.; Torres-Benítez, A.; et al. Phenolic Profile, Antioxidant and Enzyme Inhibition Properties of the Chilean Endemic Plant Ovidia pillopillo (Gay) Meissner

(Thymelaeaceae). Metabolites 2022, 12, 90. https://doi.org/10.3390/ metabo12020090

Academic Editor:

Gabriele Capodaglio

Received: 6 December 2021

Accepted: 17 January 2022

Published: 18 January 2022

Publisher's Note: MDPI stays neutral with regard to jurisdictional claims in published maps and institutional affiliations.

Copyright: (C) 2022 by the authors. Licensee MDPI, Basel, Switzerland. This article is an open access article distributed under the terms and conditions of the Creative Commons Attribution (CC BY) license (https:// creativecommons.org/licenses/by/ $4.0 /)$.
1 Instituto de Farmacia, Facultad de Ciencias, Campus Isla Teja, Universidad Austral de Chile, Valdivia 5090000, Chile; carmenc1012@gmail.com (C.C.); diego.gonzalez@alumnos.uach.cl (D.A.G.-C.); ruth.barrientos@alumnos.uach.cl (R.B.); aljotobe19@hotmail.com (A.T.-B.)

2 Laboratorio de Química Orgánica y Productos Naturales, Facultad de Ciencias Agronómicas, Universidad de Tarapacá, Av. General Velásquez 1775, Arica 1000000, Chile; cparra@uta.cl

3 Departamento de Química Orgánica y Fisicoquímica, Facultad de Ciencias Químicas y Farmacéuticas, Universidad de Chile, Olivos 1007, Casilla 233, Santiago 6640022, Chile; javier.romero@ciq.uchile.cl

4 Laboratorio de Química de Productos Naturales, Instituto de Química de Recursos Naturales, Universidad de Talca, Talca 3460000, Chile

5 Departamento de Química, Facultad de Ciencias, Universidad de Chile, Las Palmeras 3425, Nuñoa, Santiago 7800024, Chile; areche@uchile.cl

6 Departamento de Ciencias Químicas, Universidad Andres Bello, Campus Viña del Mar, Quillota 980, Viña del Mar 2520000, Chile; bsepulveda@uc.cl

7 Departamento de Química, Facultad de Ciencias Básicas, Universidad de Antofagasta, Antofagasta 1240000, Chile; jorge.borquez@uantof.cl

8 Center for Interdisciplinary Studies on the Nervous System (CISNe), Universidad Austral de Chile, Valdivia 5090000, Chile

* Correspondence: mwalter@utalca.cl (M.W.P.); mario.simirgiotis@uach.cl (M.J.S.); Tel.: +56-999835427 (M.J.S.)

+ These authors contributed equally to this work.

\begin{abstract}
Ovidia pillopillo (Lloime) is an endemic species of the Valdivian Forest of Chile. Little is known on the chemistry and biological activity of this plant. In this study, the phenolic profile, antioxidant capacities and enzyme inhibition capacities (against tyrosinase and cholinesterase) of the plant were investigated for the first time. The phenolic profile of the plant was obtained by UHPLC-MS fingerprinting with high resolution, which showed the presence of several flavonoids and coumarins. The antioxidant potential was measured by FRAP and ORAC (45.56 $\pm 1.32 ; 25.33 \pm 1.2 \mu$ mol Trolox equivalents/g dry plant, respectively) plus ABTS and DPPH methods $\left(\mathrm{IC}_{50}=9.95 \pm 0.05\right.$ and $6.65 \pm 0.5 \mu \mathrm{g} / \mathrm{mL}$, respectively). Moreover, the flavonoid and phenolic contents were determined (57.33 \pm 0.82 and $38.42 \pm 1.32, \mu \mathrm{g}$ of Trolox and quercetin equivalents $/ 100 \mathrm{~g}$ dry weight, respectively). The ethanolic extract showed cholinesterase $\left(\mathrm{IC}_{50}=1.94 \pm 0.07\right.$ and $2.73 \pm 0.05 \mu \mathrm{g} / \mathrm{mL}$, for AChE and BuChE, respectively) and tyrosinase $(4.92 \pm 0.05 \mu \mathrm{g} / \mathrm{mL})$ enzyme inhibition activities. Based on these in vitro studies, in silico simulations were performed, which determined that the major compounds as ligands likely docked in the receptors of the enzymes. These results suggest that Ovidia pillopillo produce interesting special coumarins and flavonoids, which are potential candidates for the exploration and preparation of new medicines.
\end{abstract}

Keywords: toxic plants; daphnetin; coumarins; glycosyl flavonoids; cholinesterase inhibition; UHPLC-PDA-OT-MS/MS analysis; antioxidants; endemic species

\section{Introduction}

Ovidia pillopillo, local name Lloime (Synonyms: Daphne pillopillo C. Gay), is an endemic plant from Valdivia's temperate forest that is very purgative and emetic (Figure 1). The 
plant is a dioecious shrub with upright and bushy branches and gray bark that grows up to $700 \mathrm{~m}$ above sea level and reaches a height of $7 \mathrm{~m}$. It bears white and scented flowers that appear in terminal or apical fascicles, and the leaves are alternating, subcoriaceous, oblong and elliptical evergreen leaves of 2 to $8 \mathrm{~cm}$ long [1]. The plant's bark, fruits and leaves are all therapeutic (generally as vomitive, for constipation and treatment of syphilis), but in high doses are toxic [1,2].The plant has been employed since the ancient Mapuche pre-Columbian era, it was thrown into the sea and river waters to numb and catch fish. The infusion from the bark causes diarrhea, but the infusion from the same flowers work as an antidote. Extracts of this plant showed antifungal activity against the pathogenic soil fungi Rhizoctonia solani [3]. The toxic activity of the plant is attributed to daphnin (daphnetin 7- $\beta$-D-glucopyranoside) [1], a toxic coumarin constituent of the Daphne species. Moreover, daphnetin (7,8-dihydroxycoumarin), a major bioactive component extracted from the genus Daphne, was devoid of toxicity and showed antimicrobial properties $[4,5]$. Those interesting coumarins serve as chemotaxonomical markers of Daphne and Ovidia species $[6,7]$.
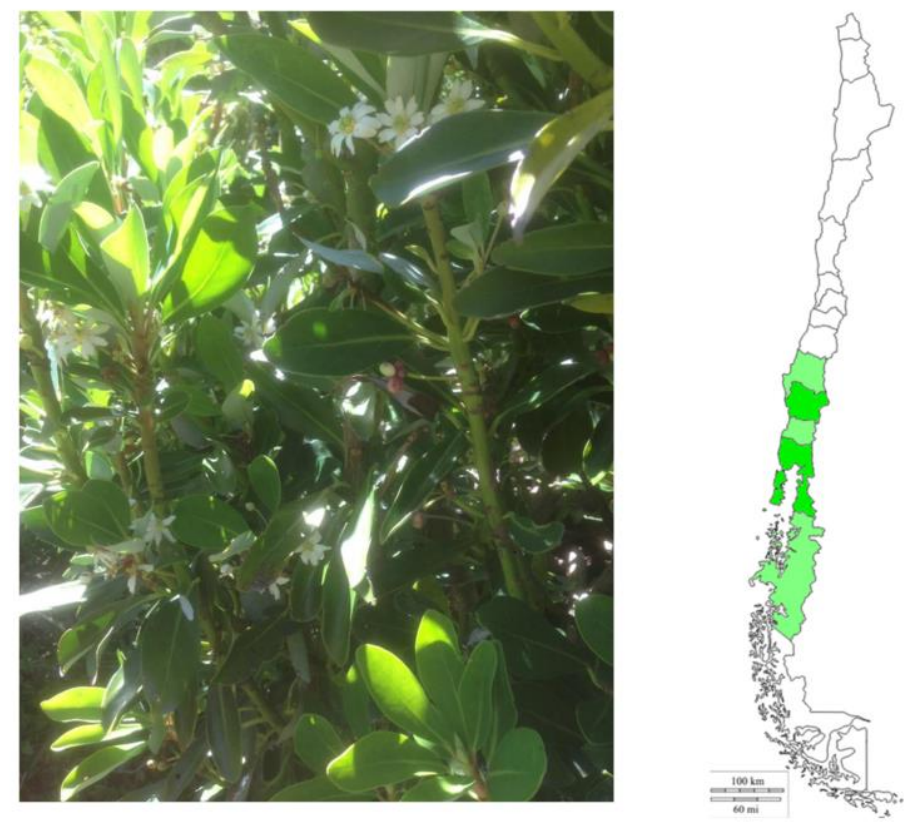

Figure 1. Picture of O. pillopillo collected at parque Oncol, Valdivia in November 2018 and zone of distribution in Chile.

To date, no UHPLC fingerprinting of the phenolic metabolites contained in Lloime (O. pillopillo) have been reported. As far as we know, there are also no scientific reports concerning to the antioxidant and enzyme inhibition potential of extracts from the plant. Our group recently investigated the enzyme inhibitory properties plus the antioxidant and chemical fingerprinting of several Chilean native plants and fruits [8-12]. Following our studies on South American plants, we now report the phenolic fingerprinting from ethanolic extracts of Lloime leaves by UHPLC-MS analysis, antioxidant activity and enzyme inhibitory potential (against cholinesterase and tyrosinase) for the first time.

\section{Results}

\subsection{UHPLC-OT-MS Analysis of Lloime (O. pillopillo)}

An ultra-high resolution liquid chromatography Orbitrap MS analysis UHPLC-PDAOT-MS/MS combining full MS spectra and MS $^{n}$ experiments revealed the presence of thirtytwo compounds in Lloime, all of them reported for the first time. The composition of the extracts included phenolics acids, fatty acids, and several characteristic coumarins. Some of these compounds were identified by spiking experiments with available standards (Table 1). 
The analyses were confirmed using MS/MS data and comparing the MS fragments with those from the available bibliography. Figure 2 shows an UHPLC-DAD-MS chromatograms of Lloime from the Valdivian Forest, Chile. The structures of some of these compounds are depicted in Figure 3. Figure S1 (Supplementary Material): Shows Full MS spectra and structures of several compounds detected in O. pillo- pillo.

Table 1. UHPLC-PDA-MS identification of the ethanolic extract from Lloime (Ovidia pillopillo).

\begin{tabular}{|c|c|c|c|c|c|c|c|c|}
\hline 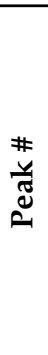 & 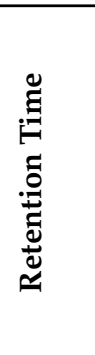 &  & 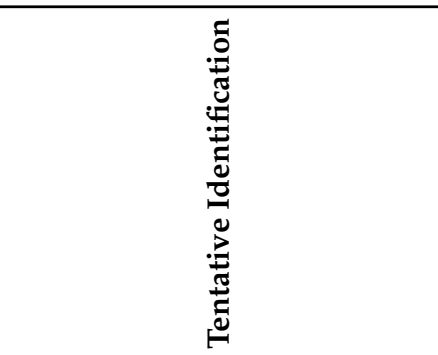 & 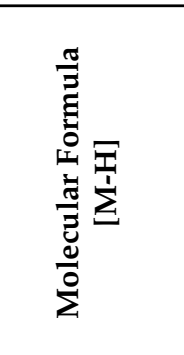 & 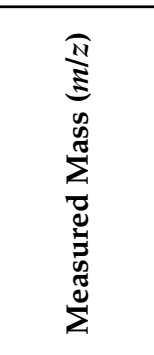 & 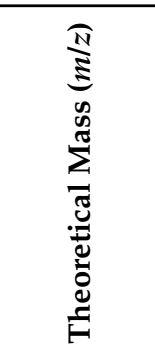 & 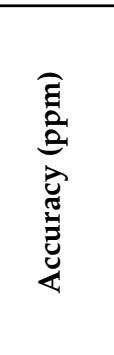 & 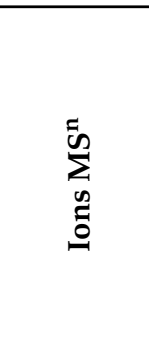 \\
\hline 1 & 1.45 & $227-272$ & Quinic acid & $\mathrm{C}_{7} \mathrm{H}_{11} \mathrm{O}_{6^{-}}$ & 191.05610 & 191.05610 & 1.385 & 175.06064 \\
\hline 2 & 1.79 & 226 & Isocitric acid & $\mathrm{C}_{6} \mathrm{H}_{7} \mathrm{O}_{7-}$ & 191.02007 & 191.01917 & -1.441 & 175.02426 \\
\hline 3 & 8.90 & 227 & Vanillic acid * & $\mathrm{C}_{8} \mathrm{H}_{8} \mathrm{O}_{4-}$ & 168.04117 & 168.04225 & -0.540 & 151.03951 \\
\hline 4 & 8.95 & 227-290sh-325 & $\begin{array}{l}\text { Daphnin 8-O-methyl ether, } \\
\text { (daphnetin } 7 \text { O-glucose, } \\
\text { 8-methyl ether) }\end{array}$ & $\mathrm{C}_{16} \mathrm{H}_{17} \mathrm{O}_{9-}$ & 353.08923 & 353.08779 & 2.521 & $\begin{array}{l}191.05622 \\
323.11307\end{array}$ \\
\hline 5 & 9.26 & $228-260$ & Sinapoyl glucose & $\mathrm{C}_{17} \mathrm{H}_{21} \mathrm{O}_{10^{-}}$ & 385.11575 & 385.35066 & 2.287 & $\begin{array}{l}341.06777 \\
223.05322\end{array}$ \\
\hline 6 & 10.45 & 245-295sh-324 & $\begin{array}{c}\text { Daphnin 8-O-methyl } \\
\text { ether-6"-O-methyl-glucose, } \\
\text { (daphnetin } 7 \\
\text { O-(6"-O-methyl-glucose, } \\
\text { 8-O-methyl ether) }\end{array}$ & $\mathrm{C}_{17} \mathrm{H}_{19} \mathrm{O}_{9-}$ & 367.10498 & 367.10345 & 2.621 & $\begin{array}{l}\text { 323.11307, } \\
191.05556, \\
175.03951\end{array}$ \\
\hline 7 & 10.81 & 245-295sh 325 & $\begin{array}{c}\text { 8-O-methyl daphnin, } \\
\text { (daphnetin } 7 \\
\text { O-(5"-O-methyl-glucose, } \\
\text { 8-O-methyl ether) }\end{array}$ & $\mathrm{C}_{17} \mathrm{H}_{19} \mathrm{O}_{9-}$ & 367.10492 & 367.10492 & 2.561 & $\begin{array}{l}191.05620 \\
135.04460\end{array}$ \\
\hline 8 & 10.87 & 255-355 & $\begin{array}{c}\text { Quercetin } \\
\text { 3-O-xylosyl-(1-2)-rhamnoside }\end{array}$ & $\mathrm{C}_{26} \mathrm{H}_{27} \mathrm{O}_{15^{-}}$ & 579.13782 & 579.12446 & 3.374 & 301.03524 \\
\hline 9 & 11.11 & $264-365$ & Kaempferol 3-O-rutinose & $\mathrm{C}_{27} \mathrm{H}_{29} \mathrm{O}_{15^{-}}$ & 593.15356 & 593.15356 & 5.83 & $\begin{array}{l}449.10838, \\
285.03991\end{array}$ \\
\hline 10 & 11.21 & $264-365$ & Kaempferol 3-O- $\beta$-D-glucose & $\mathrm{C}_{21} \mathrm{H}_{19} \mathrm{O}_{11^{-}}$ & 447.09503 & 447.09603 & 2.294 & $\begin{array}{l}285.03991 \\
325.05595\end{array}$ \\
\hline 11 & 11.40 & 277 & Proanthocyanidin Geranin B & $\mathrm{C}_{30} \mathrm{H}_{23} \mathrm{O}_{11^{-}}$ & 559.12659 & 559.13186 & 5.548 & $\begin{array}{l}255.06628, \\
541.11402\end{array}$ \\
\hline 12 & 11.49 & $240-340$ & Isoscoparine & $\mathrm{C}_{22} \mathrm{H}_{21} \mathrm{O}_{11^{-}}$ & 461.10895 & 461.10894 & 1.112 & $\begin{array}{l}299.05556, \\
283.02426\end{array}$ \\
\hline 13 & 11.65 & $264-365$ & Kaempferitrin & $\mathrm{C}_{27} \mathrm{H}_{29} \mathrm{O}_{14^{-}}$ & 577.15786 & 577.15845 & 5.66 & $\begin{array}{l}431.09837, \\
325.03537\end{array}$ \\
\hline 14 & 11.88 & $254-354$ & $\begin{array}{c}\text { Quercetin } \\
\text { 3-O- }(\beta-\mathrm{D} \text {-glucuronide }) * \\
\text { Quercetin }\end{array}$ & $\mathrm{C}_{21} \mathrm{H}_{18} \mathrm{O}_{13^{-}}$ & 477.06943 & 477.06691 & 3.063 & $\begin{array}{l}301.03482, \\
433.07708\end{array}$ \\
\hline 15 & 12.46 & $254-354$ & $\begin{array}{l}\text { 3-O- } \beta \text {-D-glucuronide- methyl } \\
\text { ester }\end{array}$ & $\mathrm{C}_{21} \mathrm{H}_{17} \mathrm{O}_{12-}$ & 491.08499 & 491.08470 & 6.054 & 301.03537 \\
\hline 16 & 12.51 & $270-338$ & Luteolin-7-O-glucuronide & $\mathrm{C}_{21} \mathrm{H}_{17} \mathrm{O}_{12-}$ & 461.07443 & 461.07254 & 5.269 & $\begin{array}{l}285.03991 \\
267.02934\end{array}$ \\
\hline 17 & 12.83 & $254-354$ & $\begin{array}{l}\text { Quercetin-3-O- } \beta-\mathrm{D}\left(2^{\prime \prime} \text {-acetyl }\right. \\
\text { glucuronide }\end{array}$ & $\mathrm{C}_{23} \mathrm{H}_{19} \mathrm{O}_{14^{-}}$ & 519.07990 & 519.07961 & 2.968 & 301.03529 \\
\hline 18 & 13.45 & $265-365$ & $\begin{array}{l}\text { Kaempferol-3-O- } \\
\text { neohesperidose }\end{array}$ & $\mathrm{C}_{27} \mathrm{H}_{25} \mathrm{O}_{5^{-}}$ & 593.15596 & 593.15344 & 3.423 & $\begin{array}{l}363.0770, \\
285.04843, \\
247.37323 \\
163.03951\end{array}$ \\
\hline
\end{tabular}


Table 1. Cont.

\begin{tabular}{|c|c|c|c|c|c|c|c|c|}
\hline \# & 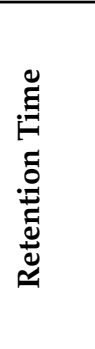 & 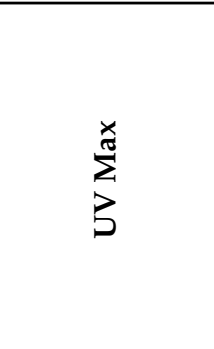 &  & 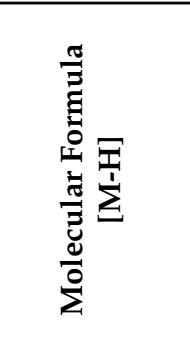 &  & 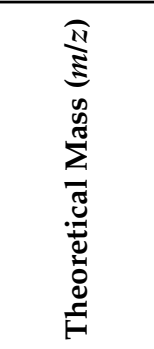 & 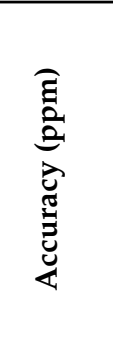 & $\sum_{\substack{\infty \\
0}}^{\infty}$ \\
\hline 19 & 13.75 & 280 & $3,8^{\prime \prime}$-Binaringenin & $\mathrm{C}_{30} \mathrm{H}_{23} \mathrm{O}_{10^{-}}$ & 543.13165 & 543.13260 & 5.665 & $\begin{array}{l}271.06119, \\
513.11910\end{array}$ \\
\hline 20 & 13.91 & $254-354$ & $\begin{array}{c}\text { Quercetin } \\
\text { 3-O- } \beta-\mathrm{D}-\left(2^{\prime \prime}-\mathrm{O}-\text { acetyl- }\right. \\
\text { glucuronide methyl ester }\end{array}$ & $\mathrm{C}_{24} \mathrm{H}_{21} \mathrm{O}_{14^{-}}$ & 533.09556 & 533.01351 & 3.058 & $\begin{array}{l}489.08342, \\
301.03412, \\
285.04843\end{array}$ \\
\hline 21 & 13.92 & $265-355$ & $\begin{array}{c}\text { Luteolin } 7-\mathrm{O}-\left(\beta-\mathrm{D}-2^{\prime} \mathrm{O} \text {-acetyl }\right. \\
\text { glucuronide }\end{array}$ & $\mathrm{C}_{23} \mathrm{H}_{19} \mathrm{O}_{13^{-}}$ & 503.08521 & 503.08521 & 3.058 & $\begin{array}{l}491.08256, \\
315.05047, \\
285.03991\end{array}$ \\
\hline 22 & 13.96 & $265-365$ & $\begin{array}{l}\text { Kaempferol 3-O- } \beta-\left(2^{\prime}-\mathrm{O}-\right. \\
\text { acetyl- } \beta-\mathrm{D} \text {-glucuronide }\end{array}$ & $\mathrm{C}_{23} \mathrm{H}_{19} \mathrm{O}_{13^{-}}$ & 503.08511 & 503.08310 & 3.093 & $\begin{array}{l}285.03991, \\
461.07200, \\
459.09273\end{array}$ \\
\hline 23 & 14.41 & $265-365$ & $\begin{array}{c}\text { Kaempferol 3-O-glucuronide } \\
\text { methyl ester }\end{array}$ & $\mathrm{C}_{22} \mathrm{H}_{19} \mathrm{O}_{12-}$ & 475.09003 & 475.08856 & 2.928 & $\begin{array}{l}285.03991, \\
429.08212\end{array}$ \\
\hline 24 & 17.06 & $248-347$ & $\begin{array}{c}\text { Luteolin } 7-\mathrm{O}-\left(\beta-\mathrm{D}-2^{\prime \prime} \mathrm{O}-\right. \\
\text { acetylglucuronide methyl } \\
\text { ester }\end{array}$ & $\mathrm{C}_{24} \mathrm{H}_{21} \mathrm{O}_{13^{-}}$ & 517.10034 & 517.10046 & 2.85 & $\begin{array}{l}285.03991, \\
461.07200, \\
355.04539\end{array}$ \\
\hline 25 & 19.33 & 227-290sh-325 & Daphnoretin & $\mathrm{C}_{19} \mathrm{H}_{12} \mathrm{O}_{7-}$ & 351.05252 & 351.05127 & 2.592 & $\begin{array}{l}\text { 207.02995, } \\
161.02441\end{array}$ \\
\hline 26 & 19.33 & $265-365$ & $\begin{array}{l}\text { Kaempferide (methyl } \\
\text { kaempferol) }\end{array}$ & $\mathrm{C}_{16} \mathrm{H}_{11} \mathrm{O}_{6^{-}}$ & 299.05740 & 299.05556 & 2.385 & $\begin{array}{l}273.03991, \\
151.00313 \\
147.04460\end{array}$ \\
\hline 27 & 20.12 & $270-338$ & Quercetin* & $\mathrm{C}_{15} \mathrm{H}_{9} \mathrm{O}_{7-}$ & 301.03513 & 301.03537 & 0.851 & $\begin{array}{l}301.03427 \\
108.02057\end{array}$ \\
\hline 28 & 20.46 & $267-335$ & Acacetin * & $\mathrm{C}_{16} \mathrm{H}_{11} \mathrm{O}_{5^{-}}$ & 283.06250 & 283.06065 & 1.852 & $\begin{array}{l}273.03991 \\
257.05599\end{array}$ \\
\hline 29 & 20.61 & $253-343$ & Hydroxyoctadecaenoic acid & $\mathrm{C}_{18} \mathrm{H}_{35} \mathrm{O}_{3-}$ & 299.25907 & 299.25940 & 4.43 & 249.14966 \\
\hline 30 & 20.63 & $253-343$ & 3,5,7-Trihydroxyoleic acid & $\mathrm{C}_{18} \mathrm{H}_{33} \mathrm{O}_{5^{-}}$ & 329.23335 & 329.23346 & 3.12 & $\begin{array}{l}119.04924 \\
\left(\mathrm{C}_{8} \mathrm{H}_{7} \mathrm{O}_{-}\right)\end{array}$ \\
\hline 31 & 22.65 & $268-330$ & Hexadecatrienoic acid & $\mathrm{C}_{16} \mathrm{H}_{25} \mathrm{O}_{2-}$ & 249.17975 & 249.18600 & -5.157 & 233.0 \\
\hline 32 & 24.11 & 220 & 2-Hydroxypalmitate & $\mathrm{C}_{16} \mathrm{H}_{31} \mathrm{O}_{3-}$ & 271.22677 & 271.22911 & 8.90 & 253.225 \\
\hline
\end{tabular}

\#: number, ${ }^{*}$ Compounds identified by co spiking with authentic standards.

Below the comprehensive metabolome analyses is explained.

\subsubsection{Coumarins}

The prominent peak 4 with UV max at 227-290sh-325 $\mathrm{nm}$ a pseudomolecular ion at $m / z$ : 353.08923 and diagnostic ion at $m / z$ : 191.05633 (daphnetin 8-methyl ether) was identified as the methyl derivative of the toxic coumarin daphnin [1], identified as daphnin 8-O-methyl ether (daphnetin $7 \mathrm{O}$-glucose, 8-methyl ether, $\mathrm{C}_{16} \mathrm{H}_{17} \mathrm{O}_{9-}$ ). In the same manner, peak 6 was identified as its methyl derivative daphnin 8-O-methyl ether-6"-O-methylglucose $\left(\mathrm{C}_{17} \mathrm{H}_{19} \mathrm{O}_{9-}\right)$, and peak 7 as its isomer daphnetin $7 \mathrm{O}-\left(5^{*}-\mathrm{O}-\right.$ methyl-glucose 8-Omethyl ether. Peak 25 was identified as the dicoumarin daphnoretin $\left(\mathrm{C}_{19} \mathrm{H}_{12} \mathrm{O}_{7-}\right)$ [6].

\subsubsection{Phenolic Acids}

Peak 3 was identified as vanillic acid $\left(\mathrm{C}_{8} \mathrm{H}_{8} \mathrm{O}_{4}{ }^{-}\right)$, and peak 5 ion at $m / z: 385.35066$ as sinapoyl glucose $\left(\mathrm{C}_{17} \mathrm{H}_{21} \mathrm{O}_{10^{-}}\right)$. 


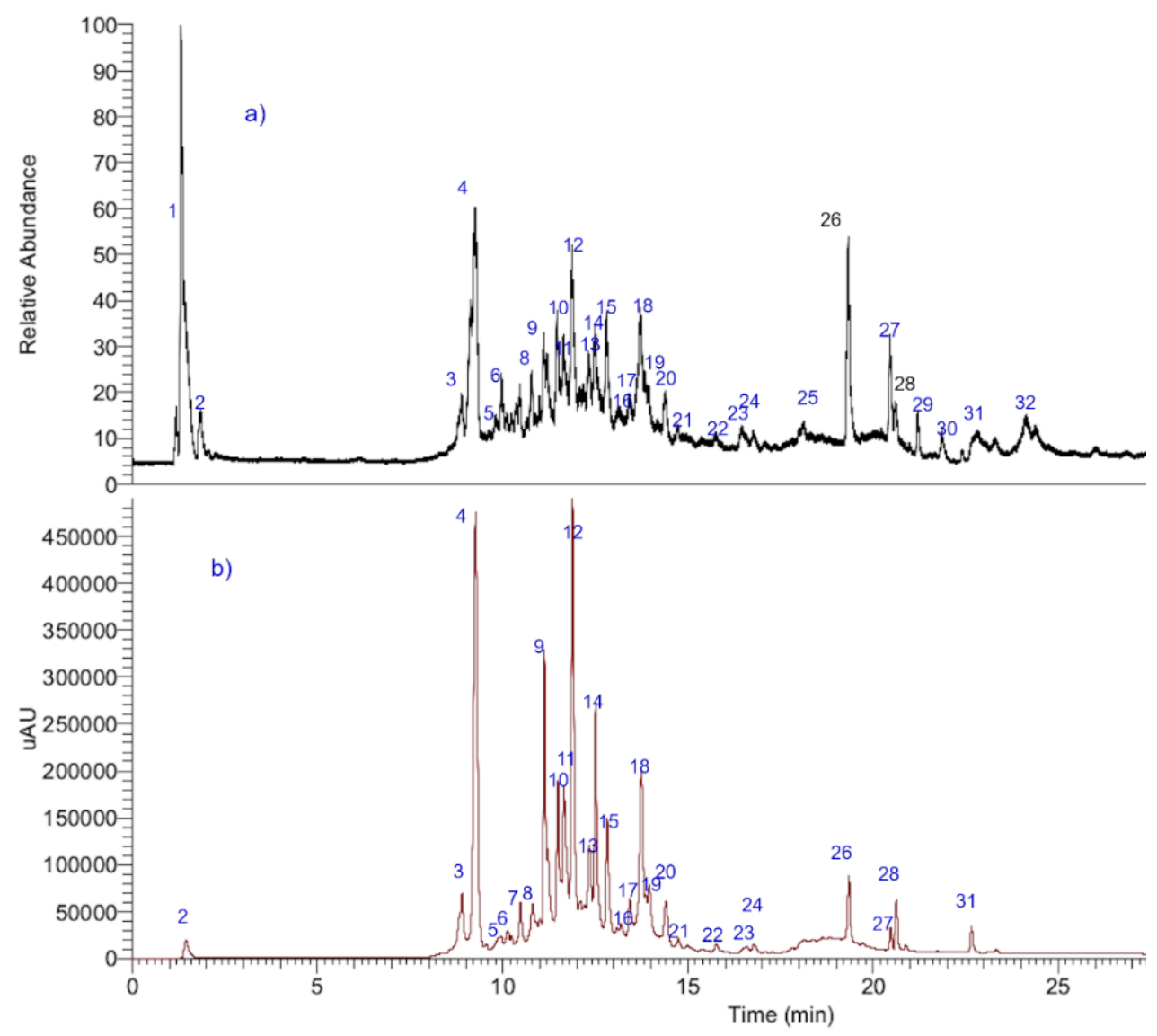

Figure 2. UHPLC chromatograms of Lloime (a) TIC, (b) UV chromatograms at $280 \mathrm{~nm}$.<smiles>[R]c1cc(O)c2c(=O)c(OC3OC([R])C(O)C(O)C3[R4])c(-c3ccc(O)c([R])c3)oc2c1</smiles>

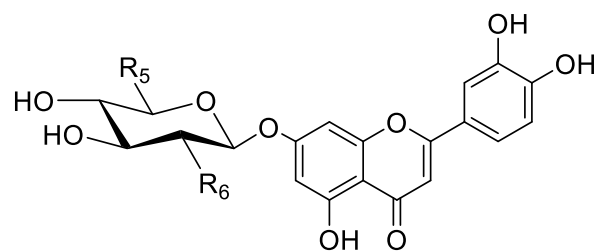

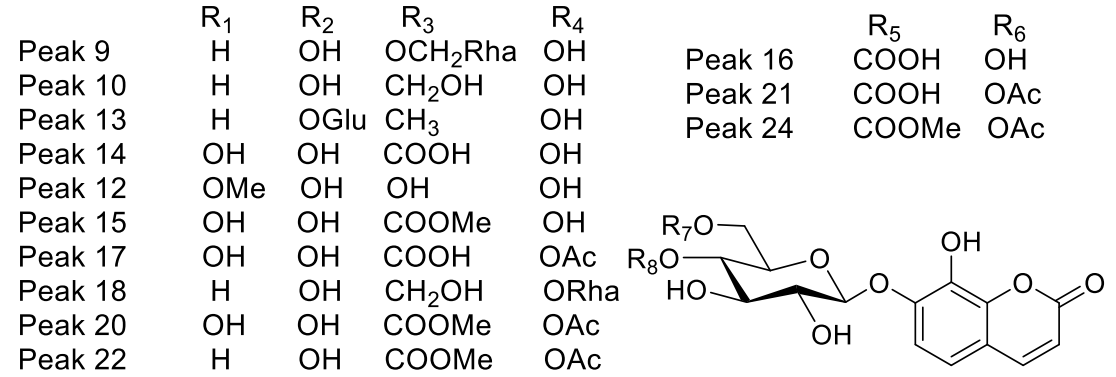<smiles>COc1cc2oc(=O)c(Oc3ccc4oc(=O)ccc4c3)cc2cc1O</smiles>

Peak 4
Peak 6
Peak 7

$\begin{array}{cc}\mathrm{R}_{7} & \mathrm{R}_{8} \\ \mathrm{H} & \mathrm{H} \\ \mathrm{Me} & \mathrm{H} \\ \mathrm{H} & \mathrm{Me}\end{array}$

Peak 25

Figure 3. Main quercetin, kaempferol, luteolin and coumarin glycosyl derivatives detected in Lloime (Ovidia pillopillo).

\subsubsection{Flavonoids}

Peak 8 showing UV vis data of flavonol $(254-354 \mathrm{~nm})$ and a parent full MS ion at $m / z$ : 579.12446 and daughter quercetin ion at $m / z: 301.03524$ was identified as quercetin 3-O- 
xylosyl-(1-2)-rhamnoside $\left(\mathrm{C}_{26} \mathrm{H}_{27} \mathrm{O}_{15^{-}}\right)$[13]; in the same manner, peak 14 was tentatively identified as the antiinflammatory quercetin 3-O- $\beta$-D-glucuronide $\left(\mathrm{C}_{21} \mathrm{H}_{18} \mathrm{O}_{13^{-}}\right)$[14], peak 18 as its acetyl derivative quercetin-3-O- $\beta-\mathrm{D}\left(2^{\prime \prime}\right.$-acetyl glucuronide $\left(\mathrm{C}_{23} \mathrm{H}_{19} \mathrm{O}_{14^{-}}\right)$, peak 16 as its methyl derivative quercetin 3-O- $\beta$-D-glucuronide-methyl esther $\left(\mathrm{C}_{21} \mathrm{H}_{17} \mathrm{O}_{12^{-}}\right)$ and peak 21 as quercetin 3-O-(2" -O-acetyl-glucuronide methyl ester), with the formula: $\mathrm{C}_{24} \mathrm{H}_{21} \mathrm{O}_{14^{-}}$and peak 27 as quercetin. On the other hand, several compounds were identified as kaempferol derivatives (Uv max 264-347 nm). Peak 9 with a parent full MS ion at $m / z$ : 593.15356 was identified as the lipid peroxidantion inhibitor kaempferol 3-O-rutinose $\left(\mathrm{C}_{27} \mathrm{H}_{29} \mathrm{O}_{15^{-}}\right)$[15] with a diagnostic kaemperol ion at $m / z: 285.03991$, and its isomer peak 18 as kaempferol-3-O-neohesperidose. Peak 10 was identified as kaempferol 3-O- $\beta$-D-glucose $\left(\mathrm{C}_{21} \mathrm{H}_{19} \mathrm{O}_{11^{-}}\right)$, peak 13 as the immunostimulatory kaempferitrin $\left(\mathrm{C}_{27} \mathrm{H}_{29} \mathrm{O}_{14^{-}}\right)$[16], peak 22 as kaempferol 3-O- $\beta-\left(2^{\prime}-\mathrm{O}\right.$-acetyl- $\beta$-D-glucuronide), with a formula: $\mathrm{C}_{23} \mathrm{H}_{19} \mathrm{O}_{13^{-}}$, peak 23 as kaempferol 3-O-glucuronide methyl ether $\left(\mathrm{C}_{22} \mathrm{H}_{19} \mathrm{O}_{12^{-}}\right)$, and peak 26 as kaempferide $\left(\mathrm{C}_{16} \mathrm{H}_{11} \mathrm{O}_{6^{-}}\right)$. Peak 16 showed UV max of luteolin (270-338 nm) and showed a deprotonated molecule at $\mathrm{m} / \mathrm{z}: 461.07254$ and was identified as the anti-inflammatory and antioxidant compound luteolin-7-O-glucuronide $\left(\mathrm{C}_{21} \mathrm{H}_{17} \mathrm{O}_{12^{-}}\right)$[17]. Similarly peak 21 showed a deprotonated molecule at $m / z$ : 503.08521 and was identified as luteolin 3-O- $\left(\beta-\mathrm{D}-2^{\prime} \mathrm{O}-\right.$ acetyl glucuronide $\left(\mathrm{C}_{23} \mathrm{H}_{19} \mathrm{O}_{13^{-}}\right)$, with a luteolin fragment at $m / z: 285.03993$, peak 24 as luteolin 7-O- $\left(\beta-\mathrm{D}-2 * \mathrm{O}\right.$-acetylglucuronide methyl ester $\left(\mathrm{C}_{24} \mathrm{H}_{21} \mathrm{O}_{13^{-}}\right)$. Peak 19 with a UV max of flavanone $(280 \mathrm{~nm})$ was identified as 3,8'-binaringenin $\left(\mathrm{C}_{30} \mathrm{H}_{23} \mathrm{O}_{10^{-}}\right)$, peak 11 as proanthocyanidin geranin $\mathrm{B}\left(\mathrm{C}_{30} \mathrm{H}_{23} \mathrm{O}_{11^{-}}\right)$, peak 12 as isoscoparine $\left(\mathrm{C}_{22} \mathrm{H}_{21} \mathrm{O}_{11^{-}}\right)$and, finally, peak 28 as acacetin $\left(\mathrm{C}_{16} \mathrm{H}_{11} \mathrm{O}_{5^{-}}\right)$.

\subsubsection{Fatty Acids}

Peak 30 with a pseudomolecular ion at $\mathrm{m} / \mathrm{z}: 329.23346$ was tentatively identified as 3,5,7-trihydroxyoleic acid $\left(\mathrm{C}_{18} \mathrm{H}_{33} \mathrm{O}_{5^{-}}\right)$, peak 29 as hydroxyoctadecaenoic acid $\left(\mathrm{C}_{18} \mathrm{H}_{35} \mathrm{O}_{3^{-}}\right)$ [18], peak 31 as hexadecatrienoic acid $\left(\mathrm{C}_{16} \mathrm{H}_{25} \mathrm{O}_{2-}\right)$ and peak 32 as 2-hydroxypalmitate $\left(\mathrm{C}_{16} \mathrm{H}_{31} \mathrm{O}_{3^{-}}\right)$.

\subsubsection{Other Compounds}

Peaks 1 was identified as quinic acid $\left(\mathrm{C}_{7} \mathrm{H}_{11} \mathrm{O}_{6^{-}}\right)$and peak 2 as isocitric acid $\left(\mathrm{C}_{6} \mathrm{H}_{7} \mathrm{O}_{7^{-}}\right)$.

\subsection{Antioxidant and Enzyme Inhibitory Capacities of Lloime}

Lloime leaves extracts were assessed in vitro for cholinesterase and tyrosinase inhibitory potential. As far as we know, no previous reports regarding anti-enzymatic potential have been published for this species. The results are summarized in Table 2 and are expressed as $\mathrm{IC}_{50}$ values $(\mu \mathrm{g} / \mathrm{mL})$. Besides, the antioxidant potential of the ethanolic extract of this plant was measured by several methods, namely FRAP and ORAC (45.56 \pm 1.32 , $25.33 \pm 1.2 \mu \mathrm{mol}$ Trolox equivalents/g dry plant, respectively), plus ABTS and DPPH methods $\left(\mathrm{IC}_{50}=9.95 \pm 0.05\right.$, and $\left.6.65 \pm 0.5 \mu \mathrm{g} / \mathrm{mL}\right)$. This was complemented with the measurements of flavonoid and phenolic contents $(57.33 \pm 0.82$ and $38.42 \pm 1.32, \mu \mathrm{g}$ of trolox and quercetin equivalents / $100 \mathrm{~g}$ dry weight, respectively).

\subsection{Docking Assays of Most Abundant Compounds}

All compounds that turned out to be the most abundant in Lloime leaves extract (Figure 4) according to the UHPLC chromatogram (Figure 2) obtained from O. pillopillo leaves extract, as well as the known cholinesterase and tyrosinase inhibitors, galantamine and kojic acid respectively, were subjected to docking assays into the acetylcholinesterase catalytic site, the butyrylcholinesterase catalytic site and the tyrosinase catalytic site, in order to rationalize their inhibitory properties through the analysis of the protein molecular interactions in the light of the experimental inhibition activities obtained (Table 2). The best docking binding energies expressed in $\mathrm{kcal} / \mathrm{mol}$ of each compound are shown in Table 3. 
Table 2. Scavenging of the 1,1-diphenyl-2-picrylhydrazyl Radical (DPPH), radical ABTS, (ABTS), Total phenolic content (TPC), Total flavonoid content (TFC) cholinesterase inhibition capacity and tyrosinase inhibition capacity of Lloime from the VIII Region of Chile. $(n=5)$.

\begin{tabular}{|c|c|c|c|c|c|c|c|c|c|}
\hline Sample & $\mathrm{DPPH}^{\mathrm{a}}$ & ABTS $^{a}$ & ORAC $^{b}$ & FRAP $^{b}$ & TPC $^{c}$ & TFC $^{d}$ & $\mathrm{AChE}^{\mathrm{e}}$ & $\mathrm{BuChE}^{\mathrm{e}}$ & $\operatorname{Tyr}^{\mathrm{e}}$ \\
\hline $\begin{array}{l}\text { Lloime } \\
\text { ethanol } \\
\text { extract }\end{array}$ & $\mathrm{IC}_{50}=6.65 \pm 0.5$ & $\mathrm{IC}_{50}=9.95 \pm 0.05$ & $25.33 \pm 1.2$ & $45.56 \pm 1.32$ & $57.33 \pm 0.82$ & $38.42 \pm 1.32$ & $1.94 \pm 0.07$ & $2.73 \pm 0.05$ & $9.92 \pm 0.05$ \\
\hline Gallic acid & $14.32 \pm 0.5$ & $1.67 \pm 0.25$ & - & - & - & - & - & - & - \\
\hline Kojic acid & - & - & - & - & - & - & - & - & $3.51 \pm 0.02$ \\
\hline Galantamine & - & - & - & - & - & - & $0.26 \underset{\mathrm{e}}{ \pm} 0.02$ & $3.82 \pm 0.02$ & - \\
\hline
\end{tabular}

a Antiradical DPPH and ABTS activities are expressed as $\mathrm{IC}_{50}$ in $\mu \mathrm{g} / \mathrm{mL} ;{ }^{\mathrm{b}}$ Expressed as $\mu \mathrm{mol}$ Trolox/g dry plant; ${ }^{c}$ Total phenolic content (TPC) expressed as $\mu \mathrm{g}$ gallic acid equivalent GAE/100 g dry weight; ${ }^{\mathrm{d}}$ Total flavonoid

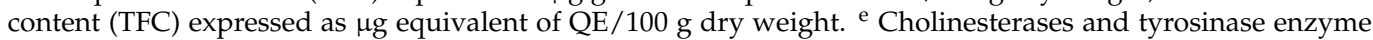
inhibitory activity in $\mathrm{IC}_{50}$ in $\mu \mathrm{g} / \mathrm{mL}$. Values in the same column are significantly different $($ at $p<0.05)$.

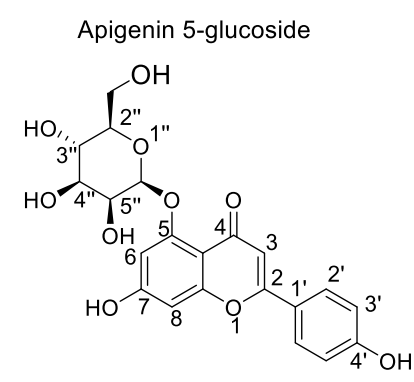

Quercetin 3-O - - -D-2" -acetylglucuronide

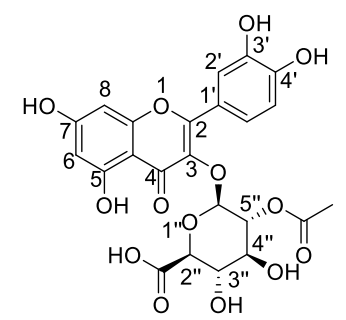

5-hydroxy-7-methoxy

-2-phenyl-4H-chromen-4-one

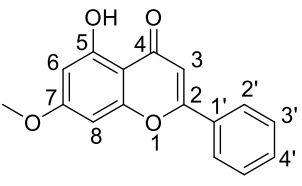

Quercetin 3-O-ß -D-2" -acetylglucuronide methyl ester

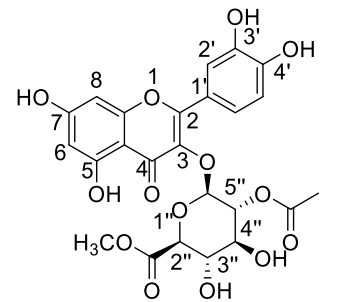

Luteolin 7,4'-dimethyl ether<smiles>COc1cc(O)c2c(=O)cc(-c3ccc(OC)c(O)c3)oc2c1</smiles>

Quercetin 3-O-(ß-D-glucuronide )

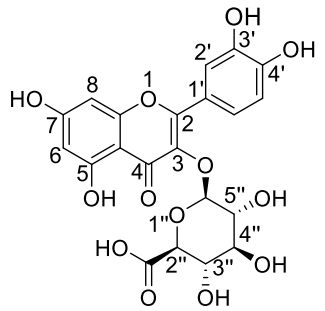

8-O-methyl daphnin, (daphnetin 7 O-(5"-O-methyl -glucose, 8-O-methyl eter)

Quercetin 3-O-ß-D -(glucuronide methyl ester)

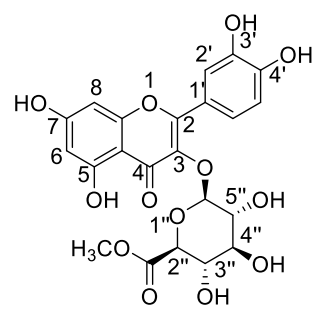

Figure 4. Main compounds in Lloime (Ovidia pillopillo) leaves used to perform docking experiments into the corresponding catalytic sites of acetylcholinesterase, butyrylcholinesterase, and tyrosinase.

Table 3. Binding energies obtained from docking experiments of most abundant compounds in Lloime leaves extract, as well as binding energies of the known inhibitors, galantamine and kojic acid over acetylcholinesterase (TcAChE) butyrylcholinesterase $(h \mathrm{BChE})$ and tyrosinase.

\begin{tabular}{|c|c|c|c|}
\hline Compound & $\begin{array}{l}\text { Binding Energy } \\
\text { (kcal/mol) }\end{array}$ & $\begin{array}{c}\text { Binding Energy } \\
\text { (kcal/mol) }\end{array}$ & $\begin{array}{c}\text { Binding Energy } \\
\text { (kcal/mol) } \\
\text { Tyrosinase }\end{array}$ \\
\hline 5-hydroxy-7-methoxy-2-phenyl-4H-chromen-4-one & -9.154 & -7.987 & -5.908 \\
\hline Luteolin $7,4^{\prime}$-dimethyl ether & -10.506 & -8.562 & -6.054 \\
\hline Apigenin 5-glucoside & -12.798 & -10.378 & -9.018 \\
\hline Quercetin 3-O-B-D-2" -acetylglucuronide & -14.064 & -10.933 & -10.333 \\
\hline $\begin{array}{c}\text { Quercetin 3-O-B-D-2" -acetylglucuronide methyl } \\
\text { ester }\end{array}$ & -15.497 & -11.803 & -9.018 \\
\hline Quercetin 3-O-(ß-D-glucuronide) & -14.144 & -12.888 & -10.038 \\
\hline Quercetin 3-O-B-D-(glucuronide methyl ester) & -14.518 & -12.169 & -9.169 \\
\hline $\begin{array}{c}\text { 8-O-methyl daphnin (daphnetin } 7 \\
\text { O-(5"O-methyl-glucose, 8-methyl ether) }\end{array}$ & -12.651 & -10.812 & -8.456 \\
\hline Galantamine & -12.989 & -7.125 & - \\
\hline Kojic acid & - & - & -6.050 \\
\hline
\end{tabular}




\subsubsection{Acetylcholinesterase (TcAChE) Docking Results}

Table 3 shows binding energies of 5-hydroxy-7-methoxy-2-phenyl-4H-chromen-4-one, luteolin 7,4'-dimethyl ether, Apigenin 5-glucoside, quercetin 3-O-B-D-2" quercetin 3-O-B-D-2" -acetylglucuronide methyl ester, quercetin 3-O-(B-D-glucuronide) and quercetin 3-O-B-D-(glucuronide methyl ester). Better energy parameters for Apigenin 5glucoside, quercetin 3-O-B-D-2" -acetylglucuronide, quercetin 3-O-B-D-2" -acetylglucuronide methyl ester, quercetin 3-O-(B-D-glucuronide) and quercetin 3-O-B-D-(glucuronide methyl ester) were obtained than with standard galantamine. Although the aforementioned compounds possess slightly better energy profiles than the known inhibitor galantamine, the fact that the Ovidia pillopillo leaves extract contain many other active compounds, including the seven that we studied by docking assays, lead into a competition among all of them for the acetylcholinesterase catalytic site; not a refined or accurate result can be obtained as if an inhibition assay were done with each one of the derivatives separately. Nonetheless, it is clear that the good energies presented by these major compounds obtained from the extract are responsible for the strong inhibitory effect exerted over the enzyme.

5-Hydroxy-7-methoxy-2-phenyl-4H-chromen-4-one and luteolin 7,4'-dimethyl ether are arranged in the same manner into the acetylcholinesterase catalytic site, which could probably explain the similar binding energy descriptors between them $(-9.154 \mathrm{kcal} / \mathrm{mol}$ and $-10.506 \mathrm{kcal} / \mathrm{mol}$, respectively). Likewise, both of these compounds are also settled similarly to quercetin 3-O-B-D-2" -acetylglucuronide, quercetin 3-O-B-D-2"-acetylglucuronide methyl ester and quercetin 3-O-B-D-(glucuronide methyl ester) in terms of geometric molecular space. Nonetheless, probably due the lack of glycoside moities in 5-hydroxy-7-methoxy-2phenyl-4H-chromen-4-one and Luteolin 7,4'-dimethyl ether, the obtained binding energies and, consequently, the inhibitory activities, are lower than for the other derivatives (Table 3 and Figure 5). The 5-hydroxy-7-methoxy-2-phenyl-4H-chromen-4-one formed one hydrogen bond with Tyr130 and two $\pi-\pi$ interactions through the phenyl moiety at position 2- of the $4 \mathrm{H}$-chromen-4-one and the amino acids Phe330 and Tyr334. On the other hand, luteolin $7,4^{\prime}$-dimethyl ether carried out two hydrogen bond interactions with Tyr121 and Tyr130, as well as a $\pi-\pi$ interaction between Trp 84 and the $4 H$-chromen-4-one core. The extra interaction with Tyr121 would explain the better binding energy profile of this derivative compared to 5-hydroxy-7-methoxy-2-phenyl-4H-chromen-4-one (Table 3).

Apigenin 5-glucoside shows a particular pattern of location into the catalytic site, and no similarities in terms of spatial arrangement were found with any of the other tested derivatives. Apigenin 5-glucoside displayed four hydrogen bond interactions with Asp72, Tyr121 and Tyr130. Besides, it can be noted that three $\pi-\pi$ interactions with Trp84 and Phe330 residues were performed by this compound (Figure 5C).

Quercetin 3-O-B-D-2"-acetylglucuronide, quercetin 3-O-B-D-2" -acetylglucuronide methyl ester, and quercetin 3-O-B-D-(glucuronide methyl ester) are arranged in similar ways, but with slight differences. Therefore, these derivatives shared some interactions with the same amino acids of acetylcholinesterase catalytic. In this sense, all three compounds, through their hydroxyl $(-\mathrm{OH})$ groups at position 7 - of the $4 H$-chromen-4-one framework, performed hydrogen bond interactions with His440. Moreover, the three of them showed $\pi-\pi$ or T-shaped interactions with Phe330 and Phe331 accordingly, except for quercetin 3-O-B-D-2"-acetylglucuronide methyl ester, which also carried out this sort of interaction with Phe290. Moreover, quercetin 3-O-B-D-2"-acetylglucuronide and quercetin $3-\mathrm{O}-\mathrm{B}-\mathrm{D}-2^{\prime \prime}$-acetylglucuronide methyl ester display $\pi-\pi$ interactions by their phenyl moieties and Trp84 amino acid. Furthermore, another hydrogen bondings carried out by these three compounds also share some common residues to perform this type of interactions; however, there are some differences due to their accommodations into the enzyme pocket. In this manner, quercetin 3-O-B-D-2" -acetylglucuronide showed five hydrogen bond interactions with Trp84, Tyr121, Tyr130 and His440 (already mentioned), quercetin 3-O-B-D-2" -acetylglucuronide methyl ester exhibited six hydrogen bond interactions with Tyr121, Asp72, Tyr334, Gly441 and His440 and quercetin 3-O-B-D-(glucuronide methyl ester) showed five hydrogen bondings with Gln 74, Tyr121, Ser122, Tyr130 and His440 
(Figure 5D,E,G). Notwithstanding, quercetin 3-O-B-D-2" -acetylglucuronide methyl ester exhibited the greatest protein-inhibitor complex stabilization, showing the best binding energy, suggesting that this compound could exert the main contribution to the inhibitory activity of Ovidia pillopillo leaves extract over the acetylcholinesterase.

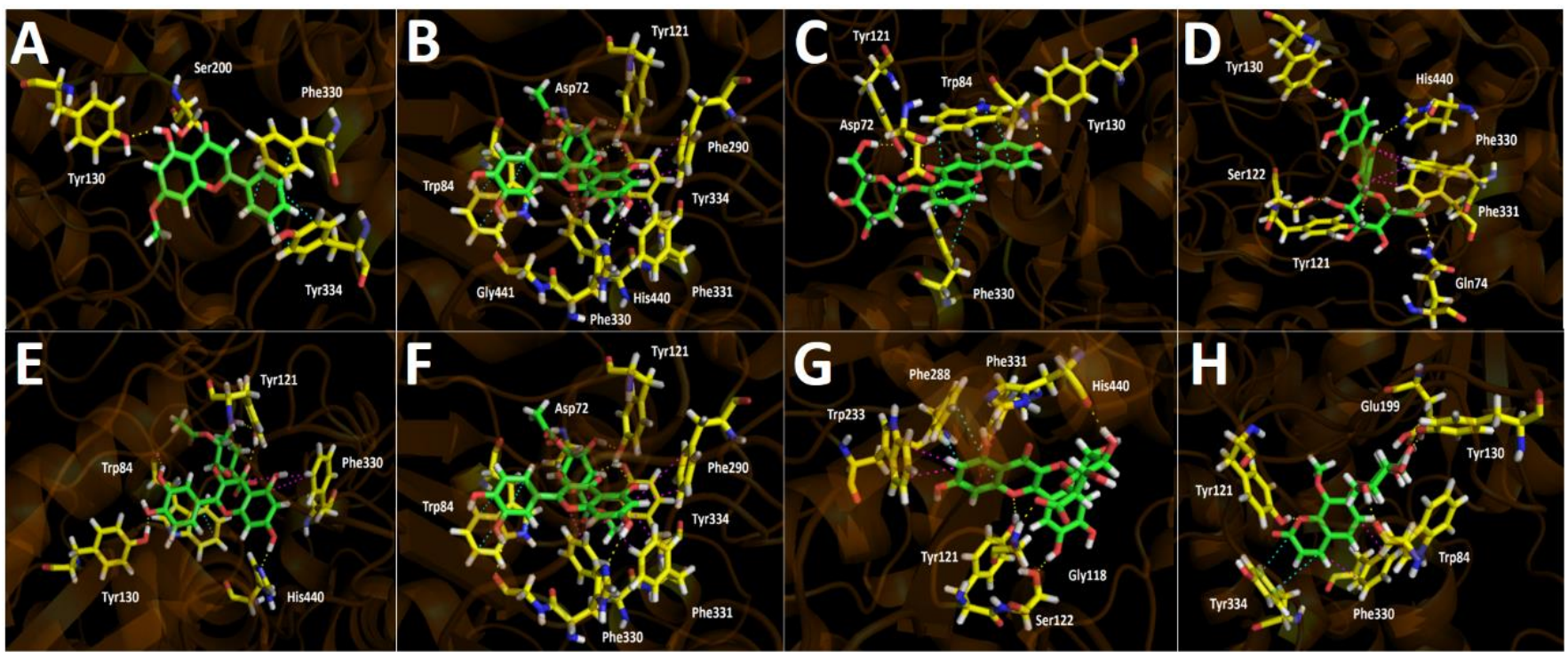

Figure 5. Predicted binding mode and predicted intermolecular interactions of most abundant compounds in Ovidia pillopillo leaves extract and the residues of Torpedo Californica acetylcholinesterase (TcAChE) catalytic site. Yellow dotted lines indicate hydrogen bond interactions, cyan dotted lines represents $\pi-\pi$ interactions, magenta dotted lines represents T-shaped interactions. (A). 5hydroxy-7-methoxy-2-phenyl-4H-chromen-4-one into the catalytic site; (B). Luteolin 7,4'-dimethyl ether into the catalytic site; (C). Apigenin 5-glucoside into the catalytic site; (D). Quercetin 3-O- $B$ -D-2" -acetylglucuronide into the catalytic site; (E). Quercetin 3-O-B-D-2"-acetylglucuronide methyl ester into the catalytic site; (F). Quercetin 3-O-(B-D-glucuronide) into the catalytic site; (G). Quercetin 3-O- $\mathrm{B}$-D-(glucuronide methyl ester) into the catalytic site; (H). 8-O-metyl daphnin, (daphnetin 7 O-glucose, 8-methyl ether) into the catalytic site.

Quercetin 3-O-(B-D-glucuronide) maintain a similar orientation related to the three aforementioned compounds; nevertheless the $4 \mathrm{H}$-chromen-4-one core of this latter derivative possess an opposite position, where the carbonyl function is inverted; therefore, it stabilizes within the catalytic site through hydrogen bond interactions with Gly118, Tyr121, Ser122 and His440, as well as by performing a $\pi-\pi$ interaction with Phe288 and two Tshaped interactions with Phe331 and Trp233 (Figure 5F).

The toxic compound 8-O-methyl daphnin (daphnetin 7 O-(5"-O-methyl-glucose), 8methyl ether) which is in the Ovidia pillopillo [1], showed a binding energy value of -12.651 $\mathrm{kcal} / \mathrm{mol}$ suggesting that this compound could exert a good acetylcholinesterase inhibition. Into the catalytic site, compound 8-O-metyl daphnin performed three hydrogen bond interactions with Trp84, Tyr121 and Tyr130, as well as a T-shaped and a $\pi-\pi$ interaction with Phe330 and Tyr334, respectively (Figure 5H).

\subsubsection{Butyrylcholinesterase ( $h \mathrm{BuChE}$ ) Docking Results}

Binding energies from docking assays over butyrylcholinesterase $(h \mathrm{BuChE})$ of the most abundant compounds from Lloime Ovidia pillopillo leaves extract showed to be less contributing compared to those obtained from acetylcholinesterase (TcAChE). Nonetheless, all compounds presented a good binding energy profile, except for 5-hydroxy-7-methoxy2-phenyl-4H-chromen-4-one, as in acetylcholinesterase (Table 3).

The compounds 5-hydroxy-7-methoxy-2-phenyl-4H-chromen-4-one and luteolin 7,4'dimethyl ether displayed analogous poses into the butyrylcholinesterase catalytic site; nonethe- 
less, they are not completely overlapped between each other, as in acetylcholinesterase experiments. Indeed, their structures are slightly tilted between them, where the phenyl ring of 5-hydroxy-7-methoxy-2-phenyl-4H-chromen-4-one is crooked in relation to the methoxyphenol ring of luteolin 7, $4^{\prime}$-dimethyl ether. Given the above, 5-hydroxy-7-methoxy2-phenyl-4H-chromen-4-one carried out one hydrogen bond interaction between the carbonyl group $(\mathrm{C}=\mathrm{O})$ of the $4 \mathrm{H}$-chromen-4-one framework and Gly116, two T-shaped interactions between the $4 \mathrm{H}$-chromen-4-one and the phenyl moiety with the residues of Trp82 and Phe329, respectively, and a $\pi$-cation interaction due the close distance between the imidazole ring of His438 and the $4 H$-chromen-4-one core. In the same way, Luteolin 7,4'-dimethyl ether performed a hydrogen bonding with ser198, a $\pi-\pi$ interaction between Trp82 and the $4 H$-chromen-4-one, as well as $\pi-\pi$ and $\pi$-cation interactions with the imidazole aromatic ring of His 438 residue and the $4 H$-chromen-4-one mentioned above.

The same manner as in acetylcholinesterase docking assays, apigenin 5-glucoside binding pose into the butyrylcholinesterase catalytic site was completely different compared to all other tested derivatives, showing two hydrogen bond interactions through its two hydroxyl groups $(-\mathrm{OH})$ at the glycoside moiety with Ser287 and two $\pi-\pi$ interactions through the $4 H$-chromen-4-one framework with Trp82 and with the phenol ring, as well (Figure 6C).

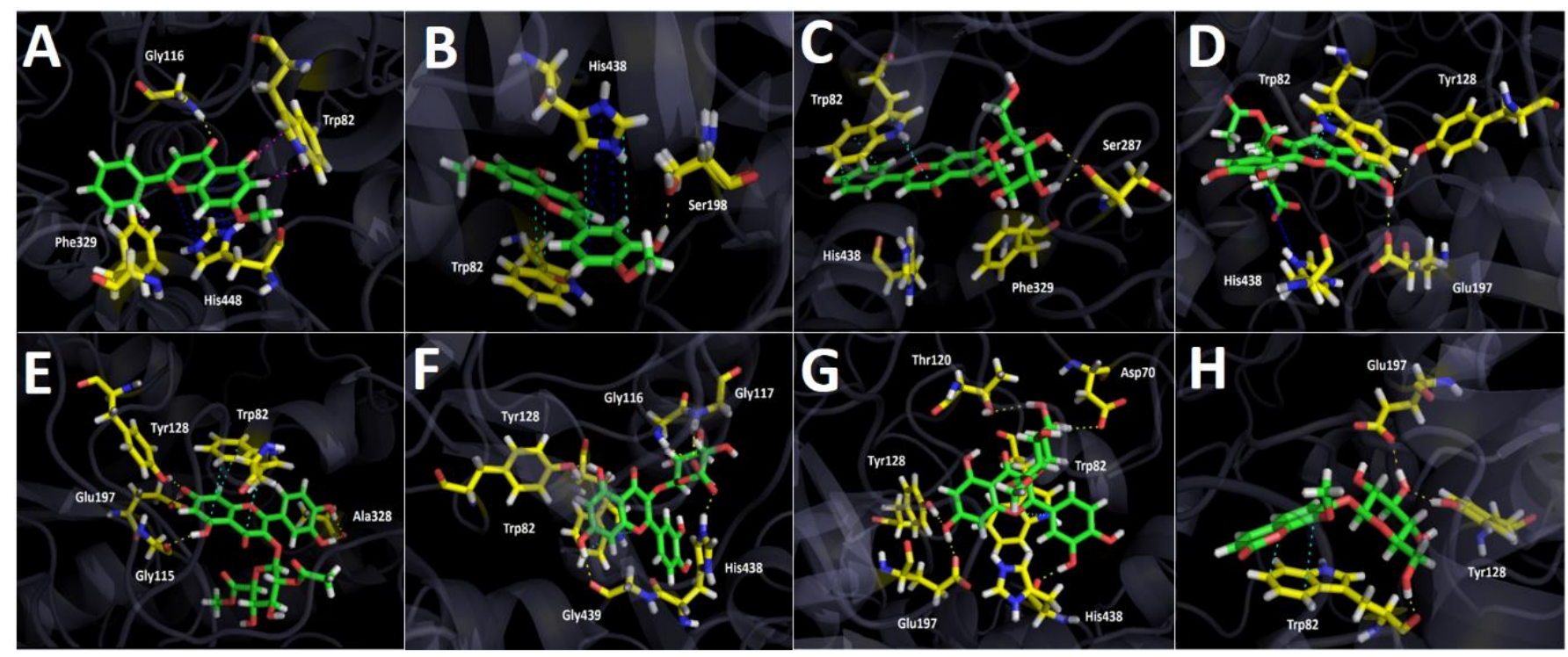

Figure 6. Predicted binding mode and predicted intermolecular interactions of most abundant compounds in Ovidia pillopillo leaves extract and the residues of Torpedo Californica acetylcholinesterase (TcAChE) catalytic site. Yellow dotted lines indicates hydrogen bond interactions, cyan dotted lines represents $\pi-\pi$ interactions, magenta dotted lines represents T-shaped interactions, blue dotted lines represents $\pi$-cation interactions. (A). 5-hydroxy-7-methoxy-2-phenyl-4H-chromen-4-one into the catalytic site; (B). Luteolin 7, $4^{\prime}$-dimethyl ether into the catalytic site; (C). Apigenin 5-glucoside into the catalytic site; (D). Quercetin 3-O-B -D-2" -acetylglucuronide into the catalytic site; (E). Quercetin 3$\mathrm{O}-ß-\mathrm{D}-2^{\prime \prime}$-acetylglucuronide methyl ester into the catalytic site; (F). Quercetin 3-O-(ß-D-glucuronide) into the catalytic site; (G). Quercetin 3-O- $\beta$-D-(glucuronide methyl ester) into the catalytic site; $(\mathbf{H})$. 8-O-metyl daphnin, (daphnetin 7 O-glucose, 8-methyl ether) into the catalytic site.

Quercetin 3-O-ß-D-2" -acetylglucuronide and quercetin 3-O- $\beta-D-2^{\prime \prime}$-acetylglucuronide methyl ester are almost spatially located in the same manner. In fact, both compounds perform hydrogen bond interactions through the oxygen atom of the hydroxyl groups at position 7 - of the $4 \mathrm{H}$-chromen-4-one and Tyr128 residue. Likewise, another hydrogen bond interaction through the hydrogen atom of the same already mentioned hydroxyl function of both derivatives are performed with Glu197. Besides, the $4 H$-chromen-4-one core of both compounds carry out a $\pi-\pi$ interaction with Trp82. According to their differences, it can 
be seen a few of them between these two derivatives, for example a $\pi$-cation interaction performed by the phenolic ring of quercetin 3-O-B-D-2" -acetylglucuronide and the amino acid His438, as well as three hydrogen bond interactions with Gly115 and Ala328 carried out by the appropriate hydroxyl functional groups of quercetin 3-O-B-D-2" -acetylglucuronide (Figure 6D,E).

Docking experiments showed that quercetin 3-O-(B-D-glucuronide) and quercetin 3-O-B-D-(glucuronide methyl ester) are settled in a resemblant orientation into the butyrylcholinesterase catalytic site, but their structures are not exactly overlapping. The latter allows that both compounds can exhibit different docking results, where Quercetin $3-\mathrm{O}-(\mathrm{B}$-D-glucuronide) carry out a $\pi-\pi$ interaction with Trp82 and owing it bears a carboxylate group in its glycoside moiety perform three strong hydrogen bond interactions with Gly116, Gly117 and His438, turning into the derivative with the best binding energy profile). Furthermore, two other same interactions with Tyr128 and Gly439 through both hydroxyl groups $(-\mathrm{OH})$ of the $4 \mathrm{H}$-chromen-4-one framework exist (Figure $6 \mathrm{~F})$. On the other hand, quercetin 3-O-ß-D-(glucuronide methyl ester) do not bear a carboxylate on its glycoside moiety; hence, it stabilizes into the butyrylcholinesterase catalytic site, performing hydrogen bond interactions through its hydroxyl functions $(-\mathrm{OH})$ and the residues of Asp70, Thr120, Tyr128, Glu197 and His438, as well as through a $\pi-\pi$ interaction between its $4 H$-chromen-4-one framework and Trp82 (Figure 6G).

Docking results for 8-O-metyl daphnin showed that this derivative fit into the butyrylcholinesterase in a different manner compared to the other tested compounds. This must be because 8-O-metyl daphnin correspond to a coumarin ( $2 \mathrm{H}$-chromen-2-one); hence, its main structure as scaffold is different. The coumarin performed three hydrogen bond interactions: one between the hydroxymethyl group of the sugar moiety and Trp82 residue, and two hydrogen bondings with a hydroxy function of the sugar moiety and the amino acids Tyr 128 and Glu197. 8-O-metyl daphnin also performed a $\pi-\pi$ interactions between the benzene ring of the coumarin and the indol ring of Trp82, contributing to the binding energy of $-10.812 \mathrm{kcal} / \mathrm{mol}$ that this compound exhibited.

\subsubsection{Tyrosinase Docking Results}

Binding energies from docking assays over tyrosinase of the most abundant compounds from Ovidia pillopillo leaves extract showed slightly better energies compared to kojic acid, that is to say, not a wide difference among the energy values was contemplated. In this sense, the extract did not exhibit a high inhibitory potency, reflecting this feature in the experimental $\mathrm{IC}_{50}$ obtained $(9.92 \pm 0.05 \mu \mathrm{g} / \mathrm{mL})$. In terms of molecular interactions among each compound and the residues of the tyrosinase catalytic site, docking descriptors suggested that the main inhibitory activity would lie in quercetin 3-O-B D-2" acetylglucuronide and quercetin 3-O-(B-D-glucuronide) derivatives. On the other hand, 5-hydroxy-7-methoxy-2-phenyl-4H-chromen-4-one docking assays over tyrosinase, just like in acetylcholinesterase and butyrylcholinesterase, showed a deficient binding energy of $-5.908 \mathrm{kcal} / \mathrm{mol}$ and no contributing interactions were presented among the residues of the catalytic site and 5-hydroxy-7-methoxy-2-phenyl-4H-chromen-4-one structure, except for a $\pi-\pi$ interaction with His263 and a hydrogen bond interaction with Met280 (Figure 7A). This phenomenon could be due to the lack of a glycoside core which bears many hydroxyl groups, ester or carboxylic functions capable of interacting with different amino acids. Thus, this compound would probably not contribute to the enzyme inhibition in a significant manner, even if it is in high proportion into the extract. In the same way, Luteolin $7,4^{\prime}$-dimethyl ether exhibited a better energy value of $-6.054 \mathrm{kcal} / \mathrm{mol}$. Although the 5-hydroxy-7-methoxy-2-phenyl-4H-chromen-4-one structure resembles to Luteolin 7,4'dimethyl ether, this last one possesses, at its phenyl ring, a hydroxyl (-OH) function and a methoxy $\left(-\mathrm{OCH}_{3}\right)$ group which, unlike 5-hydroxy-7-methoxy-2-phenyl-4H-chromen-4-one, allows one to perform hydrogen bond interactions and indeed executes them with Gly281 and Arg268, respectively. Furthermore, Luteolin 7,4'-dimethyl ether performed two $\pi-\pi$ interactions with His263 and Phe264 (Figure 7B). 


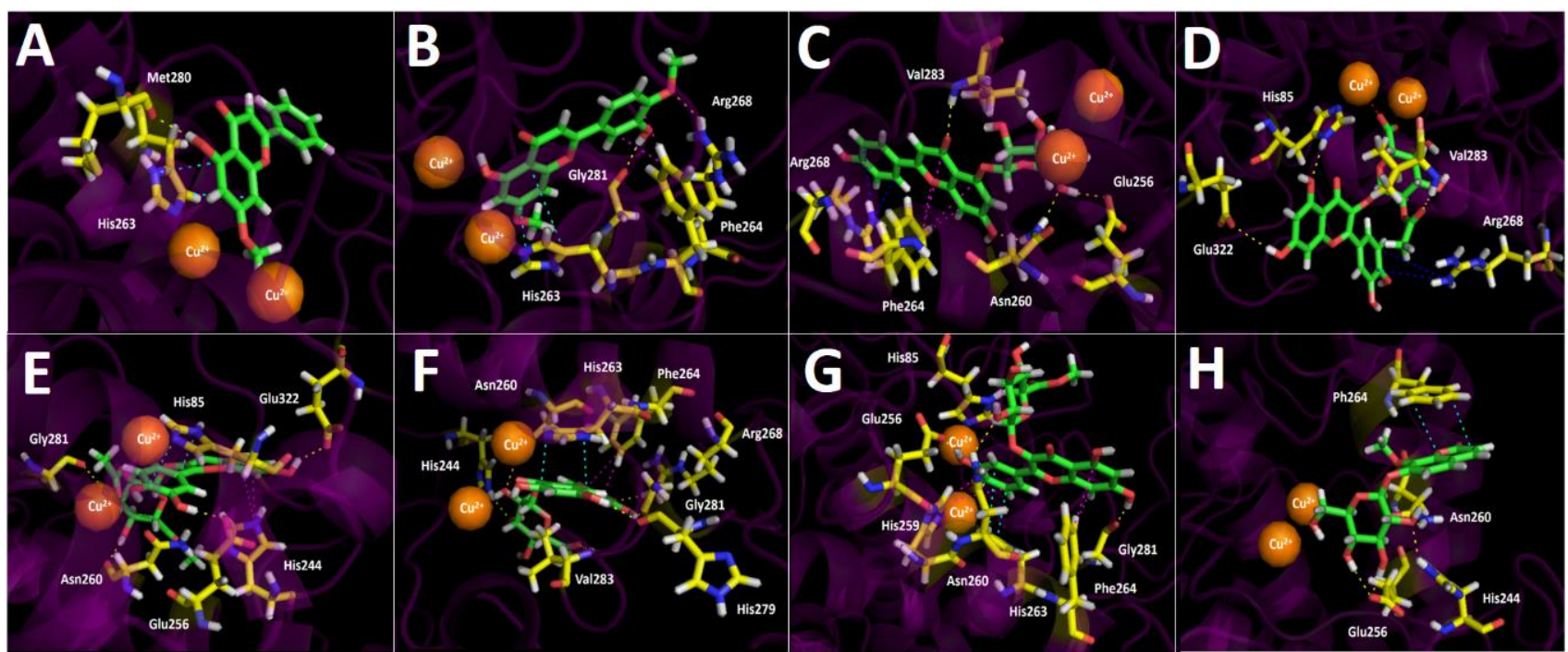

Figure 7. Predicted binding mode and predicted intermolecular interactions of most abundant compounds in O. pillopillo leaves extract and the residues of Torpedo Californica acetylcholinesterase (TcAChE) catalytic site. Yellow dotted lines indicates hydrogen bond interactions, cyan dotted lines represents $\pi-\pi$ interactions, magenta dotted lines represents T-shaped interactions, blue dotted lines represents $\pi$-cation interactions and red dotted lines represents salt bridges. (A). 5-hydroxy7-methoxy-2-phenyl-4H-chromen-4-one into the catalytic site; (B). Luteolin 7,4'-dimethyl ether into the catalytic site; (C). Apigenin 5-glucoside into the catalytic site; (D). Quercetin 3-O- $\beta$-D$2^{\prime \prime}$-acetylglucuronide into the catalytic site; (E). Quercetin 3-O-B-D-2" -acetylglucuronide methyl ester into the catalytic site; (F). Quercetin 3-O-(B-D-glucuronide) into the catalytic site; (G). Quercetin 3-O-B -D-(glucuronide methyl ester) into the catalytic site; (H). 8-O-metyl daphnin, (daphnetin 7 O-glucose, 8-methyl ether) into the catalytic site.

Apigenin 5-glucoside binding pose into the tyrosinase catalytic site once again did not match with the other derivatives assayed. However, this derivative performed three hydrogen bond interactions with Glu253, Asn260 and Val283, a T-shaped interaction with Phe264, as well as a $\pi$-cation between the phenyl moiety at position 2 - of the $4 H$-chromen4-one and Arg268 (Figure 7C).

Quercetin 3-O-B-D-2" -acetylglucuronide and quercetin 3-O-B-D-2" -acetylglucuronide methyl ester are arranged in a similar spatial manner; however, their $4 H$-chromen-4one cores are in opposite positions. Due the above, both derivatives showed different interaction patterns with the enzyme. Indeed, Quercetin 3-O- $\$-\mathrm{D}-2^{\prime \prime}$-acetylglucuronide showed three hydrogen bond interactions with His85, Val283 and Glu322, as well as a $\pi$-cation with Arg268, but also a salt bridge between one of the copper ions and the deprotonated carboxylate at its glycoside core, since the tyrosinase catalytic site possesses two copper cations in its morphology (Figure 7D). On the other hand, quercetin 3-O- 3 D-2" -acetylglucuronide methyl ester also performed hydrogen bond interactions with Glu256, Asn260, Gly281 and Glu322, as well as two $\pi-\pi$ interactions with His85 and His244; however, instead of quercetin 3-O- $3-\mathrm{D}-2^{\prime \prime}$-acetylglucuronide, the derivative quercetin 3-OB-D-2"-acetylglucuronide methyl ester did not carry out any salt bridge because it lacks a carboxylate function and, as was already mentioned, because it is arranged in an opposite manner compared to quercetin 3-O-ß-D-2" -acetylglucuronide(Figure 7E).

Quercetin 3-O-(B-D-glucuronide) and quercetin 3-O-ß-D-(glucuronide methyl ester) did not correlate in their binding poses, nor with any of the other derivatives. Nevertheless, it can be seen from Figure 7F,G that they share some interactions with the same amino acids, but with different organic functions of their structures. Therefore, quercetin 3-O-(BD-glucuronide) carried out five hydrogen bond interactions with, His244, Asn260, Arg268, His279, Gly281 and Val283, as well as a $\pi-\pi$ interaction and a T-shaped with His263 and Phe264, respectively. Quercetin 3-O-B-D-(glucuronide methyl ester) performed three 
hydrogen bond interactions with Glu256, Asn260 and Gly281, a $\pi-\pi$ interaction with His263 and two t-shaped interactions with His259 and Phe264 residues (Figure 7G).

The compound 8-O-metyl daphnin, considering its binding energy value $(-8.456 \mathrm{kcal} / \mathrm{mol})$, could be expected to behave as a potent tyrosinase inhibitor. As in butyrylcholinesterase, this coumarin derivative is arranged in a different manner into the tyrosinase catalytic site in comparison to all other tested compounds. This last feature means that the main interactions performed by the 8-O-metyl daphnin were three hydrogen bond interactions, through the hydroxy groups of the sugar moiety and the amino acids His244, Glu256 and Asn260 and a $\pi-\pi$ interaction performed between the $2 \mathrm{H}$-chromen-2-one framework and Phe264.

Finally, in order to summarize the information, Figure 8 shows the main interactions in a two-dimensional diagram of the compound with the best binding energy profile of all derivatives found in high proportion within the O. pillopillo leaves extract and, consequently, the one that would contribute the most to the inhibitory activity. Each better compound, according to docking experiments, are shown into the catalytic sites of acetylcholinesterase, butyrylcholinesterase and tyrosinase enzymes, respectively.
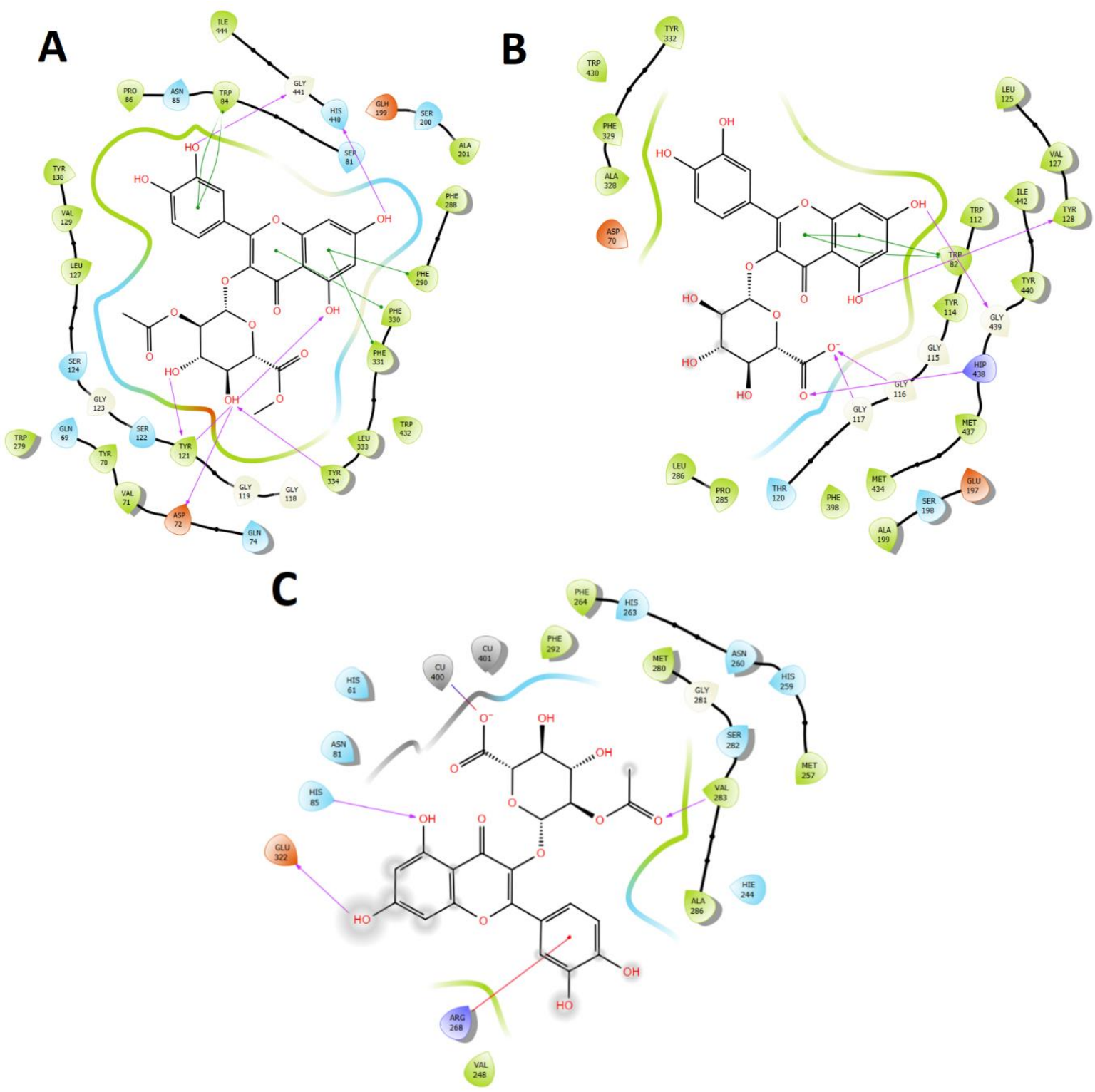

Figure 8. Two-dimensional diagram of (A). Most active compound: Quercetin 3-O-B-D-2"'-acetylglucuronide 
methyl ester (related to docking binding energy) and its main interactions into the acetylcholinesterase (TcAChE) catalytic site. (B). Most active compound: Quercetin 3-O-(B-D-glucuronide) (related to docking binding energy) and its main interactions into the butyrylcholinesterase $(h \mathrm{BuChE})$ catalytic site. (C). Most active compound: Quercetin 3-O-B D-2" -acetylglucuronide (related to docking binding energy) and its main interactions into the tyrosinase catalytic site. Purple arrows represents hydrogen bond interactions, green lines represents $\pi-\pi$ interactions and red lines represents $\pi$-cation interactions.

\section{Discussion}

The use of plants rich in phenolic constituents has been important over the years to prevent neurodegenerative diseases due to the high content of polyphenolics. The ethanolic extract of Lloime showed cholinesterase $\left(\mathrm{IC}_{50}=1.94 \pm 0.07\right.$ and $2.73 \pm 0.05 \mu \mathrm{g} / \mathrm{mL}$, for $\mathrm{AChE}$ and $\mathrm{BuChE}$, respectively) and tyrosinase (4.92 $\pm 0.05 \mu \mathrm{g} / \mathrm{mL})$ enzyme inhibition activities and several detected flavonoids and coumarin are the probable responsible constituents for the reported activity. The plant also showed potent antioxidant capacity (Table 2) by several complementary assays. Regarding the metabolites identified in the ethanolic extract of $\mathrm{O}$. pillopillo, some reports have indicated that, for example, the presence of coumarins such as daphnetin and daphnin are cholinesterase inhibitors helpful in Alzheimer's disease [19], can also be active in the treatment of Parkinson's disease [20], as well as cancer [21], and show other interesting activities in which oxidative stress may be involved. Those compounds were regarded as antibacterial, antifungal, antothrombotic, antiinflammatory, and can inhibit the enzymes cyclooxygenase, lipooxygenase and monoamine oxidase (MAO) [20]. Regarding the other compounds identified in the extract of this plant, glycosylated quercetin derivatives such as quercetin 3-O-glucuronide and isorahmnetin-3-O-glucuronide were reported to show acetylcholinesterase inhibitory activity, with $\mathrm{IC}_{50}$ values of 8.2 and $23.2 \mu \mathrm{M}$, respectively [22], those compounds also showed anti tyrosinase activity [23]. In this research,. we found cholinesterase and tyrosinase inhibitory activities of the ethanolic extract and all detected derivatives mentioned above showed good binding energies over acetylcholinesterase, even comparable to the reference compound galantamine in the docking calculations, including the reported toxic compound 8-O-methyl daphnin (daphnetin 7 O-(5"-O-methyl-glucose), 8-methyl ether), which showed a binding energy value of $-12.651 \mathrm{kcal} / \mathrm{mol}$ suggesting that this compound could exert a good acetylcholinesterase inhibition. The ethanolic extract of this plant showed potential for the preparation of nutraceuticals or natural remedies.

\section{Materials and Methods}

\subsection{Chemicals}

Ultra-pure water ( $<5 \mu \mathrm{g} / \mathrm{L}$ TOC) was obtained from a water purification system Arium 126 61316-RO plus an Arium 611 UV unit (Sartorius, Goettingen, Germany). Methanol (HPLC grade) and formic acid (puriss. p.a. for mass spectrometry) were obtained from J. T. Baker (Phillipsburg, NJ, USA). Chloroform (HPLC grade) was obtained from Merck (Santiago, Chile). HPLC standards (Quercetin 3-O-( $\beta$-D-glucuronide, vanillic acid and chlorogenic acid, quercetin, acacetin, all standards with purity higher than $95 \%$ by HPLC) were obtained from Sigma-Aldrich Chem. Co. (St Louis, MO, USA) or Extrasynthèse (Genay, France). Gallic acid (purity > 98\%), 6-hydroxy-2,5,7,8-tetramethylchromane-2carboxylic acid (Trolox)(purity > 97\%), 2,2'-azinobis(3-ethylbenothiazoline-6-sulfonic acid) diammonium salt (ABTS), 2,2-diphenyl-1-picrylhydrazyl (DPPH), Folin-Ciocalteu reagent 2,4,6-tri(2-pyridyl)-s-triazine (TPTZ), aluminum chloride, iron (III) chloride hexahydrate, (4-(2-hydroxyethyl)-1-piperazineethanesulfonic acid (HEPES), ethylenediaminetetraacetic acid (EDTA), adenosine 5'-triphosphate (ATP) disodium salt, acetylcholinesterase from Electrophorus electricus (electric eel) and butyrylcholinesterase from equine serum were from Sigma-Aldrich ${ }^{\circledR}$ (Santiago, Chile). Calcium chloride, sodium carbonate, sodium hydroxide, sodium nitrite, and potassium persulphate were obtained from Merck ${ }^{\circledR}$ (Chile). Acetone, galanthamine, kojic acid, zileuton, sodium acetate trihydrate, and glacial acetic 
acid were from Merck ${ }^{\circledR}$ (Chile). HPLC reagents, formic acid, ethyl acetate, and n-hexane were form Merck ${ }^{\circledR}$ (Chile).

\subsection{Plant Material}

Samples of the aerial parts (stems and leaves) of Ovidia pillopillo were collected during the months of September of the year 2018 in the capital city of Los Ríos Valdivia, close to being on the way to Oncol Park, Chile. The aerial parts were dried at room temperature and stored in the absence of light and heat. A voucher specimen was deposited in the "Laboratorio de Productos Naturales of the Universidad Austral de Chile" (voucher number OP-9-12-18).

\subsection{Preparation of the Ethanolic Extract of O. pillopillo}

The extract was prepared with dried and milled plant (stem and leaves) and absolute ethanol was employed, extracting $10 \mathrm{~g}$ of plant for $20 \mathrm{~min}$ with $50 \mathrm{~mL}$ ethanol (three times) with sonication. The extracts were combined, filtered, and concentrated in vacuo at $40{ }^{\circ} \mathrm{C}$ (yield 15\%), and resulting gummy residue was stored at $-80{ }^{\circ} \mathrm{C}$ for its further use.

\subsection{Ultra-High Resolution Liquid Chromatography Orbitrap MS Analysis} (UHPLC-PDA-OT-MS/MS) and Analysis Conditions

The analysis was performed with a UHPLC-high-resolution MS machine (Thermo Dionex Ultimate 3000 system with PDA detector controlled by Chromeleon 7.2 software hyphenated with a Thermo Q-exactive MS focus) with a RP-18 column (Thermo, Germany, $150 \mathrm{~mm} \times 2.1 \mathrm{~mm} \times 2, .5 \mu \mathrm{m}$ particle size) at $25^{\circ} \mathrm{C}$. The detection wavelengths were 270 , 250, and $330 \mathrm{~nm}$, and photodiode array detectors set from $200 \mathrm{~nm}$ to $800 \mathrm{~nm}$. Mobile phases were $1 \%$ formic aqueous solution (A) and acetonitrile $1 \%$ formic acid (B). The gradient program started at 5\% B at time zero, was maintained at $7 \%$ B for 5 min, went to $40 \%$ B for $10 \mathrm{~min}$, kept at $40 \%$ B for $15 \mathrm{~min}$, went to $80 \%$ B for $5 \mathrm{~min}$, kept at $80 \%$ B for $15 \mathrm{~min}$ and, finally, returned to the initial conditions within $15 \mathrm{~min}$ for column equilibration prior to each injection. The flow rate was $1.00 \mathrm{~mL} / \mathrm{min}$. The extract $(5 \mathrm{mg})$ was dissolved in methanol $(2 \mathrm{~mL})$ and filtered through a $200 \mu \mathrm{m}$ PTFE filter. Ten $\mu \mathrm{L}$ of this solution was injected in the instrument, considering all specifications (LC parameters and MS parameters) as reported [24]. Briefly, the parameters are as follows: sheath gas flow rate, 75 units; auxiliary gas unit flow rate, 20; capillary temperature, $400{ }^{\circ} \mathrm{C}$; auxiliary gas heater temperature, $500{ }^{\circ} \mathrm{C}$; spray voltage, $2500 \mathrm{~V}$ (for ESI-); and S lens, RF level 30. Full scan data in positive and negative modes were acquired at a resolving power of 70,000 FWHM at $\mathrm{m} / \mathrm{z} 200$. The mass scan range was between of $100-1000 \mathrm{~m} / z$; automatic gain control (AGC) was set at $3 \times 10^{6}$ and the injection time was set to $200 \mathrm{~ms}$. The chromatographic system was coupled to MS with a source II heated electro-nebulization ionization probe (HESI II). The nitrogen gas carrier (purity $>99.999 \%$ ) was obtained from a Genius NM32LA (Peak Scientific, Billerica, MA, USA) used as damping plus collision and gas. Mass calibration was performed once a day in both negative and positive modes to ensure working mass $5 \mathrm{ppm}$ of accuracy. For the positive mode, a mixture of caffeine $(1 \mathrm{mg} / \mathrm{mL}, 20 \mu \mathrm{L})$ and N-butylamine $(1 \mathrm{mg} / \mathrm{mL}, 100 \mu \mathrm{L})$ was used, while a mixture of sodium dodecyl sulfate $(1 \mathrm{mg} / \mathrm{mL}, 100 \mu \mathrm{L})$ and taurocholic acid sodium salt $(1 \mathrm{mg} / \mathrm{mL}, 100 \mu \mathrm{L})$ (Sigma-Aldrich, Darmstadt, Germany) was used for the negative mode. In addition, Ultramark 1621 (Alpha Aezar, Stevensville, MI, USA) was used as the reference compound ( $1 \mathrm{mg} / \mathrm{mL}, 100 \mu \mathrm{L})$. These compounds were dissolved in a mixture of acetic acid $(100 \mu \mathrm{L})$, acetonitrile $(5 \mathrm{~mL})$, water: methanol (1:1) (5 mL) (Merck, Santiago, Chile), and $20 \mu \mathrm{L}$ of the mixture were infused using a Chemyx Fusion $100 \mu \mathrm{L}$ syringe pump (Thermo Fisher Scientific, Bremen, Germany.

\subsection{Determination of Total Phenolics and Flavonoids Content}

The total content of phenolics and flavonoids compounds present in ethanolic extract of Lloime was determined by means of the Folin-Ciocalteu and $\mathrm{AlCl}_{3}$ tests respectively using a Synergy HTX microplate reader (Biotek, Winoosky, VT, USA) [25]. The evaluated 
concentrations of the extracts were $1 \mathrm{mg} / \mathrm{mL}(10 \mu \mathrm{L})$. The results were obtained with curves of standards (gallic acid (GA) and quercetin (Q), curves from 1 to $250 \mu \mathrm{g} / \mathrm{mL}, \mathrm{R}^{2}=0.99$ ) and expressed as micrograms gallic acid equivalent per $100 \mathrm{~g}$ dry weight ( $\mu \mathrm{g}$ GAE/100 $\mathrm{g}$ for phenolics compounds and micrograms quercetin equivalent per $100 \mathrm{~g}$ dry weight ( $\mu \mathrm{g} \mathrm{QE} / 100 \mathrm{~g}$ dry weight) for flavonoids. The values from triplicates were reported as the mean \pm SD.

\subsection{Antioxidant Capacities of Lloime}

Antioxidant capacities of extracts from Lloime were performed by FRAP, TEAC, ORAC and DPPH [25], each assay in triplicate.

\subsubsection{ABTS Assay}

The ABTS free radical scavenging assay was performed as reported [25]. Briefly a solution of $7 \mathrm{mM}$ ABTS (2,2'-azino-bis (3-ethylbenzothiazoline-6-sulphonic acid)) and a solution of $2.45 \mathrm{mM}$ potassium persulfate in water were mixed in a $1: 1$ ratio $(v / v)$ and incubated at room temperature for $16 \mathrm{~h}$ in the dark for the formation of the ABTS radical. After this period, a volume of $275 \mu \mathrm{L}$ of solution was mixed thoroughly with $25 \mu \mathrm{L}$ of standard or the samples, and the absorbance recorded at $734 \mathrm{~nm}$ using a microplate reader after $5 \mathrm{~min}$. Gallic acid was used as a reference standard (from 1 to $100 \mu \mathrm{g} / \mathrm{mL}$ ); a curve of extract was plotted (from 8 to $750 \mu \mathrm{g} / \mathrm{mL}$ ). The results are expressed as $\mathrm{IC}_{50}$, in $\mu \mathrm{g}$ of the extract or standard per $\mathrm{mL}$. The values are reported as the mean $\pm \mathrm{SD}$.

\subsubsection{DPPH Assay}

DPPH free radical-scavenging activity was determined as previously reported [25]. A solution of DPPH $400 \mathrm{mM}$ was prepared and using a volume of $150 \mu \mathrm{L}$ of this solution thoroughly mixed with $50 \mu \mathrm{L}$ of standard or the samples, the absorbance was recorded at $515 \mathrm{~nm}$ using a microplate reader and 96-well plates $30 \mathrm{~min}$ later. Gallic acid was used as a reference standard (from 1 to $100 \mathrm{mg}$. $\mathrm{mL}$ ); curves of extracts of $O$. pillopillo (from 8 to $600 \mu \mathrm{g} / \mathrm{mL}$ ) were prepared. The results are expressed as $\mathrm{IC}_{50}$, in $\mu \mathrm{g}$ of the extract or standard per $\mathrm{mL}$. The values are reported as the mean $\pm \mathrm{SD}$.

\subsubsection{Ferric Reducing/Antioxidant Power the FRAP Assay}

A previously validated method was employed [26]. Quantification was performed using a standard curve of the antioxidant Trolox (from 1 to $250 \mu \mathrm{g} / \mathrm{mL}, \mathrm{R} 2=0.99$ ). The measurement was performed using a volume of $290 \mu \mathrm{L}$ of extract in a well of the micro-plate reader and absorbance was measured at $593 \mathrm{~nm}$ after $5 \mathrm{~min}$. The results were expressed in $\mu \mathrm{mol}$ of Trolox equivalents per $\mathrm{g}$ of dry plant. The experiments were performed in triplicates and the values are expressed as the mean $\pm \mathrm{SD}$.

\subsubsection{ORAC Assay}

The ORAC assay was performed as previously described [26]. AAPH was used as peroxyl generator. The fluorescence of fluorescein disodium (FL) of each cycle was recorded. Parameters for the plate reader were: orbital shaking (4 mm shake width), cycle time, $210 \mathrm{~s}$; position delay, $0.3 \mathrm{~s}$; cycle number, 35; shaking mode, $8 \mathrm{~s}$ before each cycle; injection speed, $420 \mu \mathrm{L} / \mathrm{s}$. Values were calculated by using a quadratic regression equation between the Trolox or sample concentration and net area under the FL decay curve. Data are expressed as micromoles of Trolox equivalents (TE) per gram of sample ( $\mu \mathrm{mol}$ of TE/g).

The area under curve (AUC) was calculated as

$$
\mathrm{AUC}=(0: 5+\mathrm{f} 4 / \mathrm{f} 3+\mathrm{f} 5 / \mathrm{f} 3+\mathrm{f} 6 / \mathrm{f} 3+\cdots+\mathrm{f} 32 / \mathrm{f} 4+\mathrm{f} 33 / \mathrm{f} 4) \times \mathrm{CT}
$$

where $\mathrm{f} 3$ = fluorescence reading at cycle $3 ; \mathrm{fn}=$ fluorescence reading at cycle $\mathrm{n}$; and $\mathrm{CT}$, cycle time in minutes. 


\subsection{Cholinesterase Enzymes (ChE and BuCHe) Inhibition}

The inhibitory activity of cholinesterase enzymes was measured using the Ellman's method as previously reported [25]. Briefly, DTNB was dissolved in buffer Tris- $\mathrm{HCl}$ at $\mathrm{pH} 8.0$ containing $0.1 \mathrm{M} \mathrm{NaCl}$ and $0.02 \mathrm{M} \mathrm{MgCl}_{2}$. Then, a filtered sample solution dissolved in deionized water $\left(50 \mu \mathrm{L}, 2 \mathrm{mg} \mathrm{mL}^{-1}\right)$ was mixed with $125 \mu \mathrm{L}$ of 5-dithiobis(2-nitrobenzoic) acid (DTNB), acetylcholinesterase (AChE), or butyrylcholinesterase (BuChE) solution $(25 \mu \mathrm{L})$ dissolved in Tris- $\mathrm{HCl}$ buffer at $\mathrm{pH} 8.0$ in a 96-well microplate and incubated for $15 \mathrm{~min}$ at $25^{\circ} \mathrm{C}$. Initiation of reaction was performed by the addition of acetyl-thiocholine iodide (ATCI) or butyryl-thiocholine chloride (BTCl) $(25 \mu \mathrm{L})$. In addition, a blank was prepared by adding the solution sample to all reagents without the enzyme(s) (AChE or BuChE) solutions and using as standard galantamine. The measurement was then performed at $405 \mathrm{~nm}$, after $10 \mathrm{~min}$ of reaction. The activity was expressed as $\mathrm{IC}_{50}$ in $\mu \mathrm{g} / \mathrm{mL}$ using a curve from 0.05 to $25 \mu \mathrm{g} / \mathrm{mL}$.

\subsection{Docking Simulations}

Docking simulations were carried for compounds shown in Figures 4 and 5; each one of them turned out to be the most characteristic and abundant species according to the UHPLC chromatogram (Figure 2) obtained from O. pillopillo leaves extract. First, the geometries and partial charges of every compound shown in Figure 4 were fully optimised using the DFT method with the standard basis set B3LYP-6-311G+ $(d$ p) $[27,28]$ in Gaussian 09W software [29]. Then, energetic minimizations and deprotonations were carried out using the LigPrep tool in Maestro Schrödinger suite v.11.8 (Schrödinger, LLC) [30]. Crystallographic enzyme structures of Torpedo Californica acetylcholinesterase (TcAChE; PDBID: 1DX6 code [31]), human butyrylcholinesterase ( $h$ BuChE; PDBID: 4BDS code [32]) and the Agaricus bisporus mushroom tyrosinase (tyrosinase; PDBID: 2Y9X code [33]) were downloaded from the Protein Data Bank RCSB PDB [34]. Enzyme optimizations were carried out using the Protein Preparation Wizard available in Maestro software, where water molecules and ligands of the crystallographic protein active sites were removed. In the same way, all polar hydrogen atoms at $\mathrm{pH}=7.4$ were added. Appropriate ionization states for acid and basic amino acid residues were considered. The OPLS3e force field was used to minimize protein energy, as well. The enclosing box size was set to a cube with sides of $26 \AA$ length. The centroid of selected residue were chosen based on the putative catalytic site of each enzyme, considering their known catalytic amino acids: Ser200 for acetylcholinesterase (TcAChE) [35,36], Ser198 for butyrylcholinesterase ( $h \mathrm{BuChE})[37,38]$ and His263 for tyrosinase $[33,39,40]$. The Glide Induced Fit Docking protocol has been used for the final couplings [41]. Compounds were punctuated by the Glide scoring function in the extra-precision mode (Glide XP; Schrödinger, LLC) [42] and were filtered on the basis of the best scores and best RMS values (less than 1 unit as a cutting criterion), in order to obtain the potential intermolecular interactions between compounds and the enzymes, as well as the binding mode and docking descriptors. The different complexes were visualized in a visual molecular dynamics program (VMD) and Pymol [43].

\subsection{Statistical Analysis}

The data were statistically analyzed using the commercial software GraphPad Prism (GraphPad Software Inc., v.4, (San Diego, CA, USA), Statview (SAS Institute Inc., v5.0.1, Cary, NC, USA). For all the cases, the data were expressed as mean \pm SEM and differences were considered significant at $p<0.05$ and were determined by one-way ANOVA.

\section{Conclusions}

This work determined the chemical composition and antioxidant capacity of Lloime (O. pillopillo) ethanolic extract for the first time. Interesting toxic coumarins were identified; in addition, new glycosyl flavonoids showed interesting docking in the active sites of pharmacologically important enzymes, such as tyrosinase and cholinesterase. The results from the enzyme inhibition studies demonstrated a moderate inhibition, especially for the 
typical coumarins of the genera and glycosylated flavonoids, which was supported by the full docking experiments. More research is necessary in order to isolate the compounds and to perform more in vivo tests with the pure compounds that can support the beneficial and medicinal uses of this Valdivian Mapuche Amerindian plant.

Supplementary Materials: The following are available online at https: / www.mdpi.com/article / 10.3390/metabo12020090/s1, Supplementary Material Figure S1: (a-e) Full MS spectra and structures of selected compounds (peaks 10,13-15 and 17).

Author Contributions: The responsibilities of authors were as follows: M.J.S. and D.A.G.-C. collected O. pillopillo plant and prepared the ethanolic extract; A.T.-B., M.J.S., M.W.P. and C.A., performed conceptualization of the manuscript and assays, R.B., C.C., D.A.G.-C. and M.W.P. performed formal analyses, quantified, and analyzed the data for phenolics compounds and total flavonoids. A.T.-B., D.A.G.-C., C.P. and B.S. performed the HPLC-MS and enzyme inhibition assays. J.R.-P. performed docking experiments and wrote those results, C.A., J.B., B.S. and M.J.S. statistically analyzed the data and wrote the paper. All authors have read and agreed to the published version of the manuscript.

Funding: This research was supported by grants from ANID (Fondecyt Grants 1180059 and 1220075), Chile. R.B. acknowledge funds from CONICYT PFCHA/beca doctorado nacional/2019-21191978, A.T.-B. acknowledge funds from CONICYT PFCHA/beca doctorado nacional/2020-21200989, and C.C. acknowledge Universidad Austral de Chile for a doctoral grant.

Institutional Review Board Statement: Not applicable.

Informed Consent Statement: Not applicable.

Data Availability Statement: Data is contained within the article or Supplementary Material, but raw Thermo HPLC profiles of the plant or other data can be available on author's request.

Conflicts of Interest: The authors declare no conflict of interest.

\section{References}

1. Morales, E. Vegetales venenosos que pueden provocar intoxicacion en el niño. Rev. Chil. Pediatr. 1945, 16, 307-349. [CrossRef]

2. Espinoza, E. Plantas medicinales de Chile, 4th ed.; Gay, E., Vazquez, M., Murillo, J., Gajardo, A., Eds.; Mprenta Barcelona: Santiago, Chile, 1897.

3. Tito Mansilla, J.; Tarcaya, V.P.; Cufre, I.M.; Fabrizio, M.C.; Wright, E.R.; Broussalis, A.M.; Rivera, M.C. Control of Rhizoctonia solani with extracts from Ovidia andina. Rev. Fac. Cienc. Agrar. 2018, 50, 2.

4. Nanzhen, K.; Jieying, W.; Wenwei, Z.; Xiaoping, Z.; Yingyuan, F. Toxicological studies of daphnetin. Pharmacogn. Mag. 2018, 14, 561. [CrossRef]

5. Cottiglia, F.; Loy, G.; Garau, D.; Floris, C.; Caus, M.; Pompei, R.; Bonsignore, L. Antimicrobial evaluation of coumarins and flavonoids from the stems of Daphne gnidium L. Phytomedicine 2001, 8, 302-305. [CrossRef] [PubMed]

6. Zhang, T.; Wei, F.; Liu, S.; Zhao, S.; Liu, L.; Zhao, H.; Li, Y.; Zhang, T.; Wei, F.; Liu, S.; et al. Identification and Quantification of Chemical Constituents in Daphne altaica and their Antioxidant and Cytotoxic Activities. Int. J. Agric. Biol. 2019. [CrossRef]

7. Deiana, M.; Rosa, A.; Casu, V.; Cottiglia, F.; Bonsignore, L.; Dessì, M.A. Chemical composition and antioxidant activity of extracts from Daphne gnidium L. JAOCS J. Am. Oil Chem. Soc. 2003, 80, 65-70. [CrossRef]

8. Fernández-Galleguillos, C.; Quesada-Romero, L.; Puerta, A.; Padrón, J.M.; Souza, E.; Romero-Parra, J.; Simirgiotis, M.J. Uhplcms chemical fingerprinting and antioxidant, antiproliferative, and enzyme inhibition potential of gaultheria pumila berries. Metabolites 2021, 11, 523. [CrossRef] [PubMed]

9. Barrientos, R.E.; Simirgiotis, M.J.; Palacios, J.; Paredes, A.; Bórquez, J.; Bravo, A.; Cifuentes, F. Chemical fingerprinting, isolation and characterization of polyphenol compounds from Heliotropium taltalense (Phil.) I.M. Johnst and its endothelium-dependent vascular relaxation effect in rat aorta. Molecules 2020, 25, 3105. [CrossRef] [PubMed]

10. Cifuentes, F.; Palacios, J.; Bórquez, J.; Paredes, A.; Parra, C.; Bravo, A.; Simirgiotis, M.J. Fast Isolation of Flavonoids from the Endemic Species Nolana ramosissima I.M. Johnst and Its Endothelium-Independent Relaxation Effect in Rat Aorta. Molecules 2020, 25, 520. [CrossRef]

11. Gómez, J.; Simirgiotis, M.J.; Manrique, S.; Lima, B.; Bórquez, J.; Feresin, G.E.; Tapia, A. UHPLC-HESI-OT-MS-MS Biomolecules Profiling, Antioxidant and Antibacterial Activity of the "Orange-Yellow Resin" from Zuccagnia punctata Cav. Antioxidants 2020, 9, 123. [CrossRef]

12. Barrientos, R.E.; Ahmed, S.; Cortés, C.; Fernández-Galleguillos, C.; Romero-Parra, J.; Simirgiotis, M.J.; Echeverría, J. Chemical Fingerprinting and Biological Evaluation of the Endemic Chilean Fruit Greigia sphacelata (Ruiz and Pav.) Regel (Bromeliaceae) by UHPLC-PDA-Orbitrap-Mass Spectrometry. Molecules 2020, 25, 3750. [CrossRef] 
13. Nawwar, M.A.; Hashem, A.N.; Hussein, S.A.; Swilam, N.F.; Becker, A.; Haertel, B.; Lindequist, U.; El-Khatib, A.; Linscheid, M.W. Phenolic profiling of an extract from Eugenia jambos L. (Alston)—The structure of three flavonoid glycosides-Antioxidant and cytotoxic activities. Pharmazie 2016, 71, 162-168. [CrossRef] [PubMed]

14. Park, J.Y.; Lim, M.S.; Kim, S.I.; Lee, H.J.; Kim, S.S.; Kwon, Y.S.; Chun, W. Quercetin-3-O- $\beta$-D-glucuronide suppresses lipopolysaccharide-induced JNK and ERK phosphorylation in LPS-challenged RAW264.7 cells. Biomol. Ther. 2016, 24, 610-615. [CrossRef] [PubMed]

15. Cho, E.J.; Yokozawa, T.; Rhyu, D.Y.; Kim, H.Y.; Shibahara, N.; Park, J.C. The inhibitory effects of 12 medicinal plants and their component compounds on lipid peroxidation. Am. J. Chin. Med. 2003, 31, 907-917. [CrossRef]

16. Del Carmen Juárez-Vázquez, M.; Josabad Alonso-Castro, A.; García-Carrancá, A. Kaempferitrin induces immunostimulatory effects in vitro. J. Ethnopharmacol. 2013, 148, 337-340. [CrossRef] [PubMed]

17. Cho, Y.C.; Park, J.; Cho, S. Anti-Inflammatory and Anti-Oxidative Effects of luteolin-7-O-glucuronide in LPS-Stimulated Murine Macrophages through TAK1 Inhibition and Nrf2 Activation. Int. J. Mol. Sci. 2020, 21, 2007. [CrossRef]

18. Simirgiotis, M.J.; Ramirez, J.E.; Schmeda Hirschmann, G.; Kennelly, E.J. Bioactive coumarins and HPLC-PDA-ESI-ToF-MS metabolic profiling of edible queule fruits (Gomortega keule), an endangered endemic Chilean species. Food Res. Int. 2013, 54, 532-543. [CrossRef]

19. de Souza, L.G.; Rennã, M.N.; Figueroa-Villar, J.D. Coumarins as cholinesterase inhibitors: A review. Chem. Biol. Interact. 2016, 254, 11-23. [CrossRef]

20. Stefanachi, A.; Leonetti, F.; Pisani, L.; Catto, M.; Carotti, A. Coumarin: A natural, privileged and versatile scaffold for bioactive compounds. Molecules 2018, 23, 250. [CrossRef]

21. Akkol, E.K.; Genç, Y.; Karpuz, B.; Sobarzo-Sánchez, E.; Capasso, R. Coumarins and coumarin-related compounds in pharmacotherapy of cancer. Cancers 2020, 12, 1959. [CrossRef]

22. Kim, S.Y.; Park, J.Y.; Park, P.S.; Bang, S.H.; Lee, K.M.; Lee, Y.R.; Jang, Y.H.; Kim, M.J.; Chun, W.; Heo, M.Y.; et al. Flavonoid Glycosides as Acetylcholinesterase Inhibitors from the Whole Plants of Persicaria thunbergii. Nat. Prod. Sci. 2014, 20, 191-195.

23. Lee, S.G.; Karadeniz, F.; Seo, Y.; Kong, C.S. Anti-melanogenic effects of flavonoid glycosides from limonium tetragonum (thunb.) bullock via inhibition of tyrosinase and tyrosinase-related proteins. Molecules 2017, 22, 1480. [CrossRef] [PubMed]

24. Gómez, J.; Simirgiotis, M.J.; Manrique, S.; Piñeiro, M.; Lima, B.; Bórquez, J.; Feresin, G.E.; Tapia, A. Uhplc-esi-ot-ms phenolics profiling, free radical scavenging, antibacterial and nematicidal activities of "yellow-brown resins" from Larrea spp. Antioxidants 2021, 10, 185. [CrossRef] [PubMed]

25. Barrientos, R.; Fernández-Galleguillos, C.; Pastene, E.; Simirgiotis, M.; Romero-Parra, J.; Ahmed, S.; Echeverría, J. Metabolomic Analysis, Fast Isolation of Phenolic Compounds, and Evaluation of Biological Activities of the Bark from Weinmannia trichosperma Cav. (Cunoniaceae). Front. Pharmacol. 2020, 11, 780. [CrossRef] [PubMed]

26. Larrazábal-Fuentes, M.J.; Fernández-Galleguillos, C.; Palma-Ramírez, J.; Romero-Parra, J.; Sepúlveda, K.; Galetovic, A.; González, J.; Paredes, A.; Bórquez, J.; Simirgiotis, M.J.; et al. Chemical Profiling, Antioxidant, Anticholinesterase, and Antiprotozoal Potentials of Artemisia copa Phil. (Asteraceae). Front. Pharmacol. 2020, 11, 1. [CrossRef] [PubMed]

27. Adamo, C.; Barone, V. Toward reliable density functional methods without adjustable parameters: The PBE0 model Seeking for parameter-free double-hybrid functionals: The PBE0-DH model Accurate excitation energies from time-dependent density functional theory: Assessing the PBE0 model toward reliable density functional methods without adjustable parameters: The PBE0 model. J. Chem. Phys. 1999, 110, 2889. [CrossRef]

28. Petersson, G.A.; Bennett, A.; Tensfeldt, T.G.; Al-Laham, M.A.; Shirley, W.A.; Mantzaris, J. A complete basis set model chemistry. I. The total energies of closed-shell atoms and hydrides of the first-row elements. J. Chem. Phys. 1988, 89, 2193-2218. [CrossRef]

29. Frisch, A. Gaussian 09W Reference; Gaussian: Wallingford, UK, 2009.

30. Release, S. 2: Maestro; Version 11.8; Schrdinger, LLC: New York, NY, USA, 2018. Available online: https://scirp.org/reference/ referencespapers.aspx? referenceid $=2581072$ (accessed on 4 December 2021).

31. Greenblatt, H.M.; Kryger, G.; Lewis, T.; Silman, I.; Sussman, J.L. Structure of acetylcholinesterase complexed with (-)-galanthamine at 2.3 A resolution. FEBS Lett. 1999, 463, 321-326. [CrossRef]

32. Nachon, F.; Carletti, E.; Ronco, C.; Trovaslet, M.; Nicolet, Y.; Jean, L.; Renard, P.Y. Crystal structures of human cholinesterases in complex with huprine $\mathrm{W}$ and tacrine: Elements of specificity for anti-Alzheimer's drugs targeting acetyl- and butyrylcholinesterase. Biochem. J. 2013, 453, 393-399. [CrossRef]

33. Ismaya, W.T.; Rozeboom, H.J.; Weijn, A.; Mes, J.J.; Fusetti, F.; Wichers, H.J.; Dijkstra, B.W. Crystal structure of agaricus bisporus mushroom tyrosinase: Identity of the tetramer subunits and interaction with tropolone. Biochemistry 2011, 50, 5477-5486. [CrossRef]

34. Berman, H.M.; Westbrook, J.; Feng, Z.; Gilliland, G.; Bhat, T.N.; Weissig, H.; Shindyalov, I.N.; Bourne, P.E. The Protein Data Bank Nucleic Acids Res. 2000, 28, 235-242. [CrossRef]

35. Sussman, J.L.; Harel, M.; Frolow, F.; Oefner, C.; Goldman, A.; Toker, L.; Silman, I. Atomic structure of acetylcholinesterase from Torpedo californica: A prototypic acetylcholine-binding protein. Science 1991, 253, 872-879. [CrossRef] [PubMed]

36. Silman, I.; Harel, M.; Axelsen, P.; Raves, M.; Sussman, J.L. Three-dimensional structures of acetylcholinesterase and of its complexes with anticholinesterase agents. Biochem. Soc. Trans. 1994, 22, 745-749. [CrossRef] [PubMed]

37. Nicolet, Y.; Lockridge, O.; Masson, P.; Fontecilla-Camps, J.C.; Nachon, F. Crystal Structure of Human Butyrylcholinesterase and of Its Complexes with Substrate and Products. J. Biol. Chem. 2003, 278, 41141-41147. [CrossRef] 
38. Tallini, L.R.; Bastida, J.; Cortes, N.; Osorio, E.H.; Theoduloz, C.; Schmeda-Hirschmann, G. Cholinesterase inhibition activity, alkaloid profiling and molecular docking of chilean Rhodophiala (Amaryllidaceae). Molecules 2018, 23, 1532. [CrossRef] [PubMed]

39. da Silva, A.P.; Silva, N.; de Silva, N.F.; Andrade, E.H.A.; Gratieri, T.; Setzer, W.N.; Maia, J.G.S.; da Silva, J.K.R. Tyrosinase inhibitory activity, molecular docking studies and antioxidant potential of chemotypes of Lippia origanoides (Verbenaceae) essential oils. PLoS ONE 2017, 12, e0175598. [CrossRef]

40. Chen, J.; Ye, Y.; Ran, M.; Li, Q.; Ruan, Z.; Jin, N. Inhibition of Tyrosinase by Mercury Chloride: Spectroscopic and Docking Studies. Front. Pharmacol. 2020, 11, 81. [CrossRef]

41. Sherman, W.; Day, T.; Jacobson, M.P.; Friesner, R.A.; Farid, R. Novel procedure for modeling ligand/receptor induced fit effects. J. Med. Chem. 2006, 49, 534-553. [CrossRef]

42. Friesner, R.A.; Murphy, R.B.; Repasky, M.P.; Frye, L.L.; Greenwood, J.R.; Halgren, T.A.; Sanschagrin, P.C.; Mainz, D.T. Extra Precision Glide: Docking and Scoring Incorporating a Model of Hydrophobic Enclosure for Protein-Ligand Complexes. J. Med. Chem. 2006, 49, 6177-6196. [CrossRef]

43. PyMOL. pymol.org. Available online: https://pymol.org/2/ (accessed on 6 July 2021). 